UNIVERSIDADE DE BRASÍLIA

FACULDADE DE CEILÂNDIA

PROGRAMA DE PÓS-GRADUAÇÃO EM CIÊNCIAS E TECNOLOGIAS EM SAÚDE

LUCIANE DA GRAÇA DA COSTA

\title{
CARACTERIZAÇÃO E ESTADO NUTRICIONAL DE PORTADORES DE INSUFICIÊNCIA RENAL CRÔNICA EM TRATAMENTO HEMODIALÍTICO NO DISTRITO FEDERAL
}

Dissertação apresentada como requisito parcial para obtenção de Título de Mestre pelo Programa de Pós Graduação em Ciências e Tecnologias em Saúde da Universidade de Brasília/Faculdade de Ceilândia

Área de Concentração: Promoção, Prevenção e Intervenção em Saúde.

Linha de Investigação: Estratégias Interdisciplinares em Promoção, Prevenção e Intervenção em Saúde.

Temática: Nutrição Clínica

Orientadora: Prof $^{a}$ Dr $^{a}$ Kelb Bousquet Santos

Co-Orientadora: Prof $^{a}$ Dr $^{\mathrm{a}}$ Patrícia Maria Fonseca Escalda

BRASÍLIA 
LUCIANE DA GRAÇA DA COSTA

CARACTERIZAÇÃO E ESTADO NUTRICIONAL DE PORTADORES DE INSUFICIÊNCIA RENAL CRÔNICA EM TRATAMENTO HEMODIALÍTICO NO DISTRITO FEDERAL

BRASÍLIA 
Ficha catalográfica elaborada pela Biblioteca Central da Universidade de Brasilla. Acerwo 1020951.

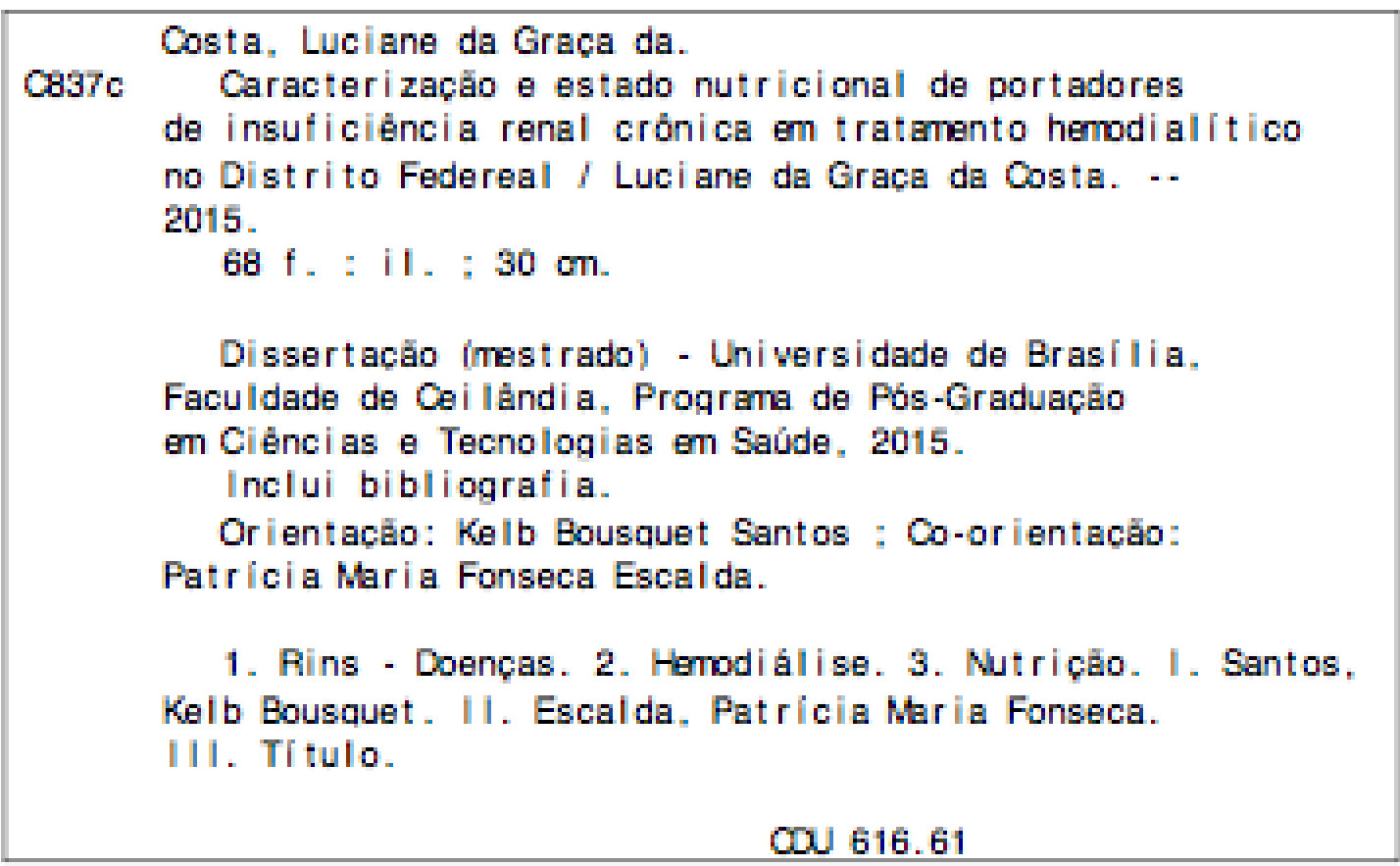




\section{CARACTERIZAÇÃO E ESTADO NUTRICIONAL DE PORTADORES DE INSUFICIÊNCIA RENAL CRÔNICA EM TRATAMENTO HEMODIALÍTICO NO DISTRITO FEDERAL}

Brasília, 04 de março de 2015.

\section{COMISSÃO EXAMINADORA}

$\operatorname{Prof}^{\mathrm{a}}$. Dr ${ }^{\mathrm{a}}$. Kelb Bousquet Santos

Programa de Pós-Graduação em Ciências e Tecnologias em Saúde UnB/FCE Presidente

$$
\begin{gathered}
\text { Prof }^{\mathrm{a}} \text {. Dr }{ }^{\mathrm{a}} \text {. Cristina Martins } \\
\text { Fundação Pró-Renal } \\
\text { Membro Externo }
\end{gathered}
$$

$\operatorname{Prof}^{\mathrm{a}}$. Dr ${ }^{\mathrm{a}}$. Marcia Cristina da Silva Magro $\mathrm{UnB} / \mathrm{FCE}$ Membro Externo 


\section{DEDICATÓRIA}

Aos meus queridos pais, Rubens Pereira da Costa (in memoriam) e Delourdes Camillo da Costa, pelo amor, incentivo e oportunidades concedidas de sempre buscar

o melhor. 


\section{AGRADECIMENTOS}

A Deus, por sempre me acalentar nos momentos de indecisão.

À minha excelente orientadora, Prof ${ }^{a}$. Dra . Kelb Bousquet Santos, pela confiança, apoio, companheirismo e incentivo nos momentos difíceis.

À querida Prof . Dr $^{a}$. Patrícia Maria Fonseca Escalda pela disponibilidade e colaboração nas orientações e apoio.

Aos pacientes e às clínicas de hemodiálise que participaram do estudo para o aprimoramento da ciência.

À aluna de iniciação científica Mariana Mendes pelo apoio e colaboração na coleta de dados.

Aos meus amigos (Tatiana Maranhão, Adriana Montemezzo, Kristy Coelho, Marcelo Azevedo, Alex Leonardo Ribeiro, José Paulo Sanctis, João Luiz Andrade, Pedro Borges de Lima, Soraia Araújo Barbosa de Lima, Vanessa Meurer, etc), pelo incentivo, apoio e disponibilidade em auxiliar nos momentos de dificuldade.

A todos vocês, a minha eterna gratidão. 


\section{SUMÁRIO}

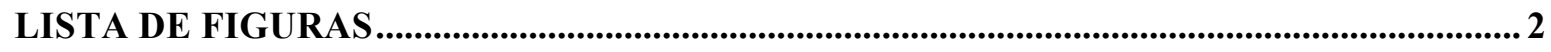

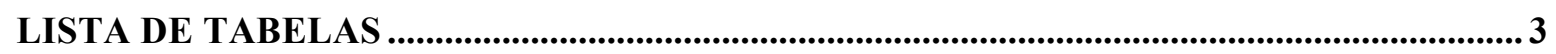

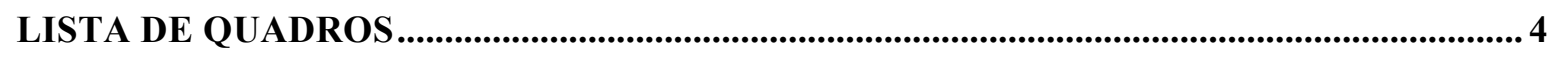

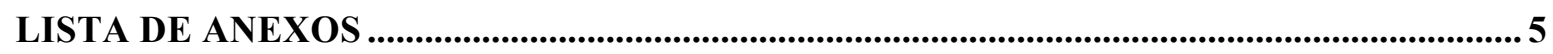

LISTA DE ABREVIATURAS E SIGLAS ................................................................................. 6

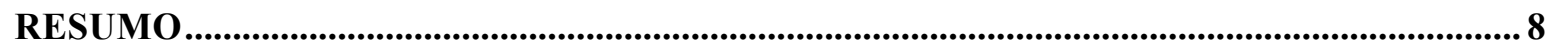

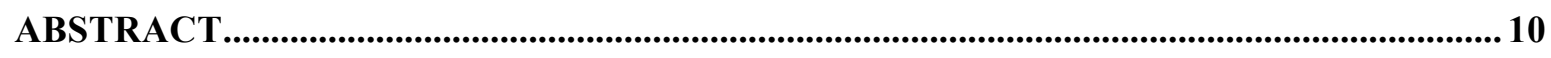

APRESENT AÇÃ

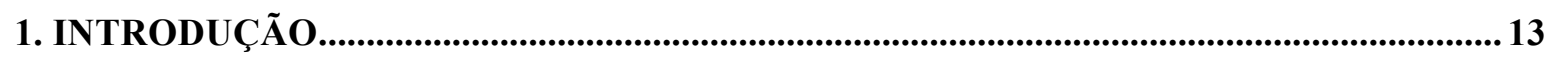

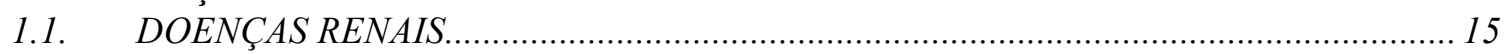

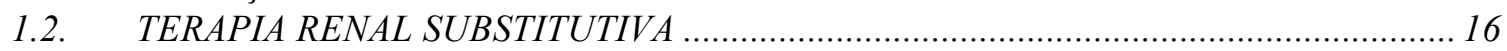

1.3. AVALIAÇÃO NUTRICIONAL NA DOENÇA RENAL CRÔNICA …............................. 18

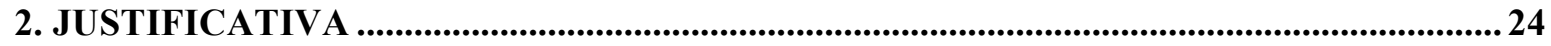

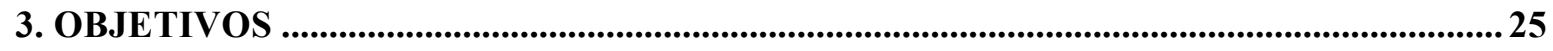

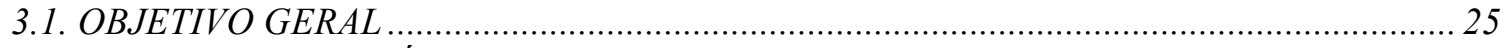

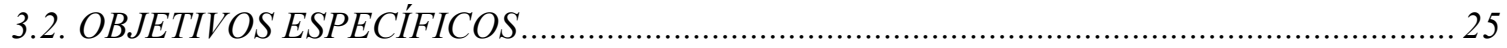

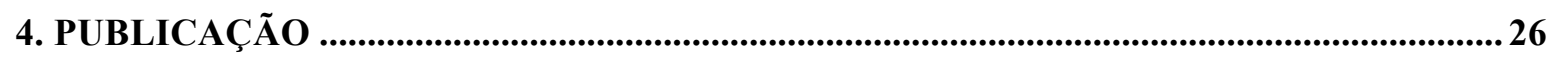

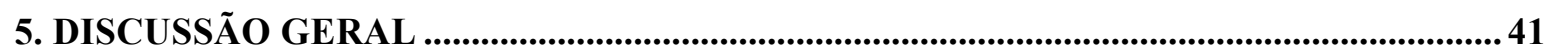

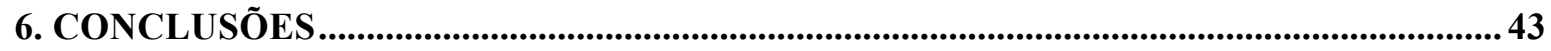

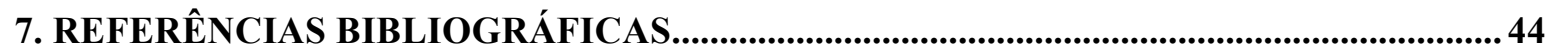




\section{LISTA DE FIGURAS}

Figura 1 - Ilustração da diálise peritoneal

Figura 2 - Correlação da albumina sérica com a CB, CMB, AMB e AMBSO 


\section{LISTA DE TABELAS}

Tabela 1 - Resultado da avaliação antropométrica da população estudada 


\section{LISTA DE QUADROS}

Quadro 1 - Estágios da DRC conforme KDIGO 2012

Quadro 2 - Critérios do estado nutricional proposto pela International Society of Renal Nutrition and Metabolism (2008) 
Anexo 1 - Termo de Consentimento Livre e Esclarecido (TCLE)

Anexo 2 - Ficha de Coleta de Dados

Anexo 3 - Normas da Revista

Anexo 4 - Comprovante de submissão do artigo para revista 
ALB - Albumina

AMB - Área Muscular do Braço

AMBSO - Área Muscular do Braço sem osso

ASG - Avaliação Subjetiva Global

CB - Circunferência do Braço

$\mathrm{CC}$ - Circunferência da Cintura

$\mathrm{CM}$ - Centímetros

CMB - Circunferência Muscular do Braço

CNES - Cadastro Nacional de Estabelecimentos de Saúde

DEP - Desnutrição energética-proteica

DF - Distrito Federal

DM - Diabetes Mellitus

DRC - Doença Renal Crônica

DRCT - Doença Renal Crônica Terminal

EN - Estado Nutricional

EUA - Estados Unidos da América

FAV - Fístula Artério-venosa

FCE - Faculdade de Ceilândia

FEPECS - Fundação de Ensino e Pesquisa em Ciências da Saúde

GDF - Governo do Distrito Federal

GNC - Glomerulonefrites

HAS - Hipertensão Arterial Sistêmica

HD - Hemodiálise

IBGE - Instituto Brasileiro de Geografia e Estatística

IMC - Índice de Massa Corporal

KDIGO - Kidney Disease: Improving Global Outcomes

KDQI - Kidney Disease Outcomes Quality Initiative

Kt/V - Depuração Fracional da Ureia

LES - Lupus Eritematoso Sistêmico

NHANES - National Health and Nutrition Examination Survey 
NKF - National Kidney Foundation

PCT - Prega Cutânea Triciptal

PNAD - Pesquisa Nacional por Amostra de Domicílios

RCQ - Relação Cintura-Quadril

SBN - Sociedade Brasileira de Nefrologia

SM - Salário Mínimo

TCLE - Termo de Consentimento Livre Esclarecido

TFG - Taxa de Filtração Glomerular

TRS - Terapia Renal Substitutiva

UnB - Universidade de Brasília

USRDS - United States Renal Data System 
A presente dissertação de mestrado objetivou descrever o perfil nutricional de portadores de Doença Renal Crônica (DRC) submetidos à hemodiálise (HD). A DRC é caracterizada pela falência irreversível da função renal, associada a alterações no equilíbrio hidroeletrolítico e ácido-básico, distúrbios hormonais e nutricionais. A HD é o tratamento dialítico mais utilizado na atualidade. A avaliação nutricional dos pacientes com DRC em HD contribui na identificação de fatores de risco para desnutrição. MÉTODOS: Para descrever o perfil da população em HD e seu estado nutricional foram coletados dados demográficos, sociais, econômicos e epidemiológicos. A população pesquisada foi de ambos os sexos, adultos $\geq 18$ anos, com mais de 3 meses de tratamento hemodialítico. Como instrumento de coleta de dados foi utilizado questionário e valores de albumina sérica e $\mathrm{Kt} / \mathrm{V}$, os quais foram obtidos no prontuário com data mais próxima da avaliação antropométrica. Após a sessão de hemodiálise foram obtidas as medidas de peso e altura; circunferências do braço (CB) e cintura (CC) e prega cutânea tricipital (PCT). Os seguintes parâmetros propostos pela International Society of Renal Nutrition and Metabolism foram utilizados para determinação de pacientes com desnutrição energética-proteica: albumina sérica $<3,8 \mathrm{~g} / \mathrm{dL}$, índice de massa corpórea (IMC) $<23 \mathrm{~kg} / \mathrm{m}^{2}$ e circunferência muscular do braço com redução $>10 \%$ em relação ao percentil 50 do NHANES II. Foram classificados com estado nutricional adequado aqueles pacientes que apresentassem valores de normalidade para os três parâmetros concomitantemente. Para análise estatística foram aplicados os testes de Kolmogorov-Smirnov e Shapiro-Wilk para avaliar a distribuição normal. Na comparação dos resultados entre gêneros foi utilizado o teste $\mathrm{T}$ de Student ou Mann-Whitney para dados paramétricos e não paramétricos, respectivamente. Para as variáveis categóricas foi utilizado o teste Qui-quadrado ou teste exato de Fisher, quando apropriado. O teste de correlação de Pearson foi utilizado para avaliar a relação entre variáveis. $\mathrm{O}$ valor de $\mathrm{p}<0,05$ foi considerado estatisticamente significativo. RESULTADOS: Foram avaliados 96 pacientes de cinco Centros de HD no Distrito Federal, sendo $57 \%$ do sexo masculino, $43 \%$ do sexo feminino e a média de idade foi de 54 \pm 15 anos. Observou-se que $54 \%$ dos pacientes eram pardos, $21 \%$ brancos, $18 \%$ negros, $4 \%$ de indígenas e 3\% não informaram esta questão. Quanto à naturalidade, $52 \%$ eram da região Nordeste, seguidos das regiões Centro-Oeste (30\%) e Sudeste (14\%), respectivamente. As causas da DRC foram atribuídas à Hipertensão Arterial Sistêmica 
(44\%), seguida de diabetes Mellitus (27\%), glomerulonefrites (9\%) ou outras patologias (19\%), destacando-se Lúpus Eritematoso Sistêmico (LES) e bexiga neurogênica como outras causas. Quando agrupado Hipertensão e Diabetes observou-se que apenas 14\% dos pacientes apresentavam estas comorbidades. O valor de albumina sérica dos pacientes avaliados foi de 3,8 $\pm 0,4 \mathrm{mg} / \mathrm{dL}$, sendo superior nos homens em comparação às mulheres $(3,9 \pm 0,4$ vs $3,7 \pm 0,4 \mathrm{mg} / \mathrm{dL}$ respectivamente; $P=0,006)$. Para avaliação da desnutrição energética-proteica foram utilizadas as metas da International Society of Renal Nutrition and Metabolism. Em relação ao IMC, dos 96 pacientes avaliados, 41 pacientes $(43 \%$; 18 mulheres) apresentaram IMC menor que $23 \mathrm{~kg} / \mathrm{m}^{2}$. Quanto à CMB, 48 pacientes $(50 \% ; 12$ mulheres; $\mathrm{P}<0,05$ vs homens) apresentaram uma diminuição em seu valor superior a $10 \%$ em comparação ao percentil 50. Para a albumina sérica, 32 pacientes (33\%; 18 mulheres) apresentaram um valor inferior a 3,8 mg/dL. Quando as três metas foram consideradas em conjunto, foram identificados 14 pacientes $(15 \% ; 57 \pm 14$ anos; 7 mulheres) com características de desnutrição energética-proteica. Encontrou-se uma relação positiva entre albumina e CB, CMB, AMB e AMB sem osso. CONCLUSÃO: A correlação positiva e significativa entre albumina e $\mathrm{CB}, \mathrm{CMB}, \mathrm{AMB}$ e $\mathrm{AMB}$ sem osso reforçam a importância da análise do perfil nutricional de pacientes nefropatas para a prevenção da desnutrição. Hipertensão e Diabetes estão presentes em 1/4 da população estudada.

Palavras- chave: doença renal crônica, hemodiálise, estado nutricional 


\section{ABSTRACT}

The major purpose of the present master thesis was to describe the nutritional profile of patients with Chronic Kidney Disease (CKD) undergoing hemodialysis (HD). CKD is characterized by failure of renal function, associated with changes in electrolyte balance and acid-base, hormonal and nutritional disorders. Hemodialysis (HD) is the most widely used dialysis today. Nutritional assessment of CRF patients on hemodialysis helps to identify risk factors for malnutrition. METHODS: Demographic, social, economic and epidemiological data were acquired to describe the profile of the population in HD and analyze their nutritional status. The research population was composed by adults $\geq 18$ years, with more than 3 months of hemodialysis. Questionnaires were used as socioeconomic data collection instrument. Serum albumin values and Kt/V were obtained from patient charts with the earliest date of anthropometric measurements. After hemodialysis session, anthropometric measurements were obtained: weight and height; arm (AC) and waist circumferences (WC) and triceps skinfold (TSF). The following parameters proposed by the International Society of Renal Nutrition and Metabolism were used for determination of patients with protein-energy malnutrition: serum albumin $<3.8 \mathrm{~g} / \mathrm{dL}$ and / or BMI $<23 \mathrm{~kg} / \mathrm{m} 2$ and / or arm muscle circumference (AMC) with reduction of $>10 \%$ relative to the 50th percentile of the NHANES II. Patients who had normal values for the three parameters simultaneously were classified as adequate nutritional status. For statistical analysis, the Kolmogorov-Smirnov and Shapiro-Wilk were applied to assess whether the data had normal distribution. We used the t-test of Student or Mann-Whitney test for parametric and non-parametric data, respectively, and to compare gender related data. For categorical variables we used the chi-square test and Fisher's exact test. The Pearson correlation test was used to assess the relationship between variables. A $p$ value $<0.05$ was considered statistically significant. RESULTS: From a total of 96 patients in five different HD centers in the Federal District, there were 57\% male, $43 \%$ female and the mean age was $54 \pm 15$ years. It was observed that $54 \%$ of patients were brown, $21 \%$ white, and $18 \%$ black. $52 \%$ were born in the Northeast region, in the Midwest $(30 \%)$ and Southeast (14\%) regions respectively. The causes of chronic renal failure were attributed to systemic hypertension (44\%), followed by diabetes mellitus (27\%), glomerulonephritis $(9 \%)$ or other disorders (19\%), highlighting lupus erythematosus (SLE) and bladder neurogenic as other causes. Only $14 \%$ of those patients had comorbidities (hypertension 
and diabetes together). The value of serum albumin of the patients was $3.8 \pm 0.4 \mathrm{mg} / \mathrm{dL}$, being higher in men when compared to women $(3,9 \pm 0,4$ vs 3,7 $\pm 0,4 \mathrm{mg} / \mathrm{dL}$ respectively; $\mathrm{P}=0.006)$. For the evaluation of protein-calorie malnutrition the International Society of Renal Nutrition and Metabolism parameters were used. Regarding BMI of 96 evaluable patients, 41 patients $\left(43 \%\right.$; 18 women) had a BMI less than $23 \mathrm{~kg} / \mathrm{m}^{2} .48$ patients $(50 \%$; 12 women; $\mathrm{P}<0.05$ vs men) had a reduction in their $\mathrm{AMC}$, more than $10 \%$ compared to the 50th percentile. 32 patients $(33 \%$; 18 women) had albumin value lower than $3.8 \mathrm{mg} / \mathrm{dL}$. When all three parameters were considered together, 14 patients were identified with $(15 \%$; $57 \pm 14 ; 7$ females) protein-energy malnutrition characteristics. We found a positive relationship between albumin and AC, AMC, MAA and MAA boneless. CONCLUSION: The thesis concluded upon a positive and significant correlation between albumin and AC, AMC, MAA and MAA boneless that reinforces the importance of the nutritional profile of nephropathic patients for preventing malnutrition. Hypertension and diabetes are present in $1 / 4$ of the population studied.

KEYWORDS: chronic kidney disease, hemodialysis, nutritional status. 


\section{APRESENTAÇÃO}

Esta dissertação foi redigida de acordo com as Normas Para Preparo da Dissertação ou da Tese Para Obtenção do Título de Mestre ou de Doutor do Programa de Pós-Graduação em Ciências e Tecnologias em Saúde, na modalidade de artigo científico. Sendo assim, o corpo da dissertação é composto dos seguintes elementos:

1. Introdução geral: descrição ampliada e detalhada sobre o tema estudado, com contextualização e apresentação da contribuição do estudo à literatura científica, justificativa e os objetivos propostos;

2. Artigo científico, redigido de acordo com as normas específicas do periódico para o qual foi submetido (Revista de Nutrição);

3. Discussão geral e conclusões, envolvendo e integrando todas as partes precedentes e os detalhes da execução do projeto não contidos no artigo científico.

4. Referências das citações não contidas no artigo científico.

5. Anexos contendo as normas de publicação do periódico ao qual foram submetidos os artigos científicos em questão e Qualis do periódico na área Interdisciplinar ou afim. 


\section{INTRODUÇÃO}

Ao longo do tempo, as transformações sociais, demográficas e econômicas ocorridas nas sociedades modificaram as condições de vida que, por sua vez, influenciaram os padrões de adoecimento da população. As doenças crônicas atualmente constituem um problema de saúde pública ameaçador para a qualidade de vida e um grande impacto no cenário econômico para os países em desenvolvimento (Schmidt, MI, Ducan, BB, et all, 2008).

Segundo Yach (2004), durante o século XX, as doenças infecciosas eram a principal causa de morte e incapacidade. No entanto, neste século, as doenças crônicas não transmissíveis, tornaram-se a principal causa de mortalidade e morbidade em todo o mundo. Dentre elas podemos citar a hipertensão (HAS) e o diabetes (DM), as quais representam os principais fatores de risco para as doenças renais crônicas (DRC), tornandoas um problema mundial de saúde pública (Cherchiglia et al, 2010).

O número de pacientes com doença renal crônica em todo o mundo está aumentando acentuadamente. No Reino Unido, a incidência anual de doença renal terminal é de cerca de 100 por 1.000 .000 populações. Esta incidência dobrou na última década e espera-se que continue a aumentar em 5 a $8 \%$ ao ano, mas permanece bem abaixo da média europeia (cerca de 135/1.000.000) e a dos Estados Unidos (336/1.000.000) (Lysaght; MJ., 2002; Ansell, D; Feest T., 2004; USRDS, 2004; Hamer, AR.; Nahas, A., 2006)

No Brasil, a Pesquisa Nacional por Amostra de Domicílios (PNAD), realizada pelo Instituto Brasileiro de Geografia e Estatística (IBGE), incluiu, no respectivo suplemento relativo à área da Saúde em 1998, questões relativas às doenças crônicas - entre elas, a doença renal crônica. A mesma edição da PNAD/2008 estimou a prevalência de DRC nas regiões Norte, de 2,8 casos por 100.000 habitantes, Nordeste de 3,9 casos por 100.000 habitantes, em contraposição a 10,7/100.000 habitantes na Região Centro-Oeste, 11,7/100.000 habitantes na Região Sudeste e 13,3 casos por 100.000 habitantes na Região Sul (Leite; Schramm, 2002; Moura et al., 2009).

Segundo Kiberd; Clase (2002), o reconhecimento da doença renal crônica nos estágios iniciais e o encaminhamento precoce ao nefrologista são fundamentais para o retardo da doença e para a diminuição do aporte de indivíduos às terapias renais substitutivas (TRS). Embora muitos trabalhos estejam sendo realizados no sentido de identificar a doença renal crônica, os estudos de base populacional ainda são escassos e 
muitas das prevalências são estimadas indiretamente (Berthoux et al., 1999; Locatelli et al., 2003; Bastos et al., 2009), procedentes de casuísticas e compostas por familiares de doentes renais crônicos e indivíduos pertencentes aos tradicionais grupos de risco para doenças cardiovasculares (Coresh et al., 2001; Levin, 2001; Sarnak et al., 2003).

Os critérios utilizados para a identificação da doença renal crônica nos estudos de rastreamento em populações diferem tanto pela escolha da população a ser rastreada quanto pelos parâmetros utilizados para identificar a presença e persistência da doença renal. As diretrizes propostas pelo Kidney Outcomes Quality Initiative (KDOQI, 2002) estabelecem que a permanência da alteração renal deva persistir, por no mínimo, três meses, para que o diagnóstico da DRC seja estabelecido. Devido a recente recomendação destas diretrizes, poucos foram os estudos nos quais este critério foi adotado, a despeito de sua importância para se excluir uma possível queda transitória da função renal (KDOQI, 2002).

Ao resgatar-se a história da nutrição na doença renal crônica, observa-se que na década de 70 surgiram os primeiros estudos identificando a desnutrição como uma condição prevalente nos pacientes com DRC, particularmente naqueles em diálise. Mas foi na década de 80 que a desnutrição foi identificada como um fator de risco para morbidade e mortalidade nesta população. A partir de então, vários métodos de avaliação nutricional passaram a ser testados para fins de diagnóstico nutricional e como preditores de desfechos clínicos (Guarnieri et al., 1980; Acchiardo et al., 1983; Marckmann, 1989; Cuppari; Kamimura, 2009).

A literatura demonstra altas taxas de morbidade e mortalidade em hemodiálise (HD), sobretudo naqueles pacientes com desnutrição. Portanto a detecção e o tratamento precoce do déficit nutricional pode reduzir o risco de infecções, outras complicações e a morte desses pacientes (Boxall; Goodship, 2008; Kalantar-Zadeh et al., 1999). Em 2010, a Sociedade Brasileira de Nefrologia divulgou o primeiro censo do estado nutricional dos pacientes em hemodiálise. Dos 5.244 pacientes avaliados, 7,5\% apresentaram algum grau de desnutrição e $37,6 \%$ com sobrepeso ou obesidade.

O estado nutricional (EN) constitui importante fator de risco na evolução clínica dessa população. Assim, é fundamental o diagnóstico do EN desses pacientes, tanto para prevenir má nutrição; quanto para indicar a intervenção mais adequada nos pacientes desnutridos (Segall et al., 2009; Kubrusly et al., 2012). 


\subsection{DOENÇAS RENAIS}

Uma nova versão das Diretrizes sobre DRC, elaboradas pelo KDIGO, foi publicada no início de 2013. Nessa nova versão das diretrizes, é recomendado classificar a doença baseando-se na causa, na categoria da taxa de filtração glomerular (TFG) e na albuminúria (Quadro 1), o que permite identificar os riscos de desfechos adversos, relacionados ao comprometimento renal e ao óbito. É destacada a importância de se estabelecer a causa da DRC, importante para se decidir qual será o tratamento específico, a fim de modificar as projeções de risco.

\begin{tabular}{|c|c|c|c|c|c|}
\hline \multicolumn{6}{|c|}{ 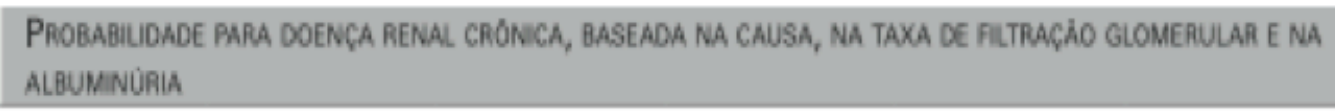 } \\
\hline Causa & \multirow{2}{*}{$\frac{\text { Categoria }}{1}$} & \multirow{2}{*}{$\begin{array}{l}\mathrm{TFGe}^{*} \\
290\end{array}$} & \multicolumn{3}{|c|}{ Albuminúria (proteinúria)*+ } \\
\hline 'Doença glomerular & & & $\mathrm{A} 1(<30)$ & $A 2(30-300)$ & $\mathrm{A} 3$ (> 300) \\
\hline ‘Doença túbulo-intersticial & 2 & $60-89$ & $\cdot$ & + & ++ \\
\hline \multirow{2}{*}{ +Doença vascular } & $3 a$ & $45-59$ & + & ++ & t++ \\
\hline & $3 b$ & $30-45$ & ++ & +++ & t++ \\
\hline 'Doença congênita & 4 & $15-29$ & +++ & t++ & t++ \\
\hline +Doença cistica & 5 & $<15$ & +++ & +++ & +++ \\
\hline
\end{tabular}

A DRC decorre de manifestações clínicas com sintomas clássicos que irão refletir na diminuição da regulação, excreção e funções endócrinas do rim (Augusto et al, 2002).

As doenças renais graves podem ser divididas em duas categorias principais: (1) lesão renal aguda, na qual os rins subitamente param de funcionar de modo total ou quase total, mas que podem em um período futuro recuperar o funcionamento quase normal, e, (2) doença renal crônica, na qual ocorre perda lenta, progressiva e irreversível da função de um número crescente de néfrons (KDIGO, 2012; Guyton, 1992). O paciente com Doença Renal Crônica Terminal (DRCT) apresenta alterações sistêmicas devido às múltiplas funções renais afetadas, doenças de base sistêmicas e às próprias complicações referentes à Insuficiência Renal (Ribeiro et al., 2008). 
Diversas são comorbidades que levam à DRC. Tanto no Brasil como no exterior, o diabetes e a hipertensão arterial constituem as principais causas de doença renal crônica. A terceira causa em ordem de frequência, são as chamadas glomerulonefrites (SBN, 2015).

A hipertensão arterial é uma das maiores causas de acidentes vasculares cerebrais, doenças cardiovasculares, insuficiência renal e morte prematura em todo o mundo. $\mathrm{O}$ controle efetivo da pressão arterial é essencial para os indivíduos hipertensos, inclusive aqueles pacientes renais crônicos. $\mathrm{O}$ seu tratamento possui forte impacto na morbidade e mortalidade, principalmente devido à doença cardiovascular (Riella e Martins, 2001).

O diabetes Mellitus é uma doença sistêmica que causa disfunção em vários órgãos e em muitos processos metabólicos (Riella e Martins, 2001). É a principal causa de doença renal em estágio terminal. Essa incidência é particularmente elevada nos Estado Unidos da América (EUA), onde cerca de 45\% dos pacientes iniciando Terapia Renal Substitutiva são diabéticos (USRDS, 2014). As complicações clássicas do diabetes são devastadoras e o impacto social bastante oneroso (Matos, Barra, Lugon, 2006).

Nas fases iniciais da DRC quando as manifestações clínicas e laboratoriais são mínimas ou ausentes, o diagnóstico pode ser sugerido pela associação de manifestações inespecíficas como fadiga, anorexia, emagrecimento, prurido, náusea ou hemólise, hipertensão, poliúria, nictúria, hematúria ou edema (Porto, 1998; Ribeiro et al., 2008). E, conforme a Portaria No 389, de 13 de março de 2014, do Ministério da Saúde, a DRC em estágio 5 (Taxa de Filtração Glomerular $(T G F)<15 \mathrm{~mL} / \mathrm{min} . / 1,73 \mathrm{~m}^{2}$ ) já denota a indicação de uma TRS (Brasil, 2014).

Assim, para o tratamento, faz-se necessário desde a psicoterapia, o direcionamento nutricional, o controle das doenças primárias, a correção dos distúrbios metabólicos, orientações adequadas sobre a doença, tratamento e autocuidado; envolvendo equipe multidisciplinar, até a adoção de uma TRS (Jones et al., 2002; Wapensky et al., 2004).

\subsection{TERAPIA RENAL SUBSTITUTIVA}

Quando cerca de apenas 10\% dos néfrons estão em funcionamento, uma TRS faz-se necessária para os pacientes com Insuficiência DRCT. Dentre os tipos incluem:

O Tratamento Conservador - A DRC aqui é definida como uma perda lenta, progressiva e irreversível da função dos rins. Até que o paciente tenha perdido cerca de 
$50 \%$ do funcionamento dos seus dois rins ele permanece praticamente sem sintomas. A partir desse ponto, vários sintomas podem ocorrer, como inchaço, pressão alta, anemia, entre outros. $\mathrm{O}$ tratamento conservador consiste em todas as medidas clínicas (remédios, modificações na dieta e estilo de vida) que podem ser utilizadas para retardar a piora da função renal, reduzir os sintomas e prevenir complicações ligadas à DRC. Apesar dessas medidas, a DRC é progressiva e irreversível. Porém, com o tratamento conservador é possível reduzir a velocidade desta progressão ou estabilizar a doença. Esse tratamento é iniciado no momento do diagnóstico da DRC e mantido a longo prazo, tendo um impacto positivo na sobrevida e na qualidade de vida desses pacientes. Quanto mais precoce começar o tratamento conservador, maiores chances para preservar a função dos rins por mais tempo (SBN, 2015).

Quando a DRC progride até estágios avançados, apesar do tratamento conservador, o paciente é preparado da melhor forma possível para o tratamento de diálise ou transplante.

A diálise peritoneal é uma opção de tratamento através do qual o processo ocorre dentro do corpo do paciente, com auxílio de um filtro natural como substituto da função renal. Esse filtro é denominado peritônio e constitui-se em uma membrana porosa e semipermeável, que reveste os principais órgãos abdominais. O espaço entre esses órgãos é a cavidade peritoneal. Um líquido de diálise é colocado na cavidade e drenado, através de um cateter (tubo flexível biocompatível), conforme Figura 1 abaixo:

Figura 1: Ilustração da diálise peritoneal

Diálise peritoneal
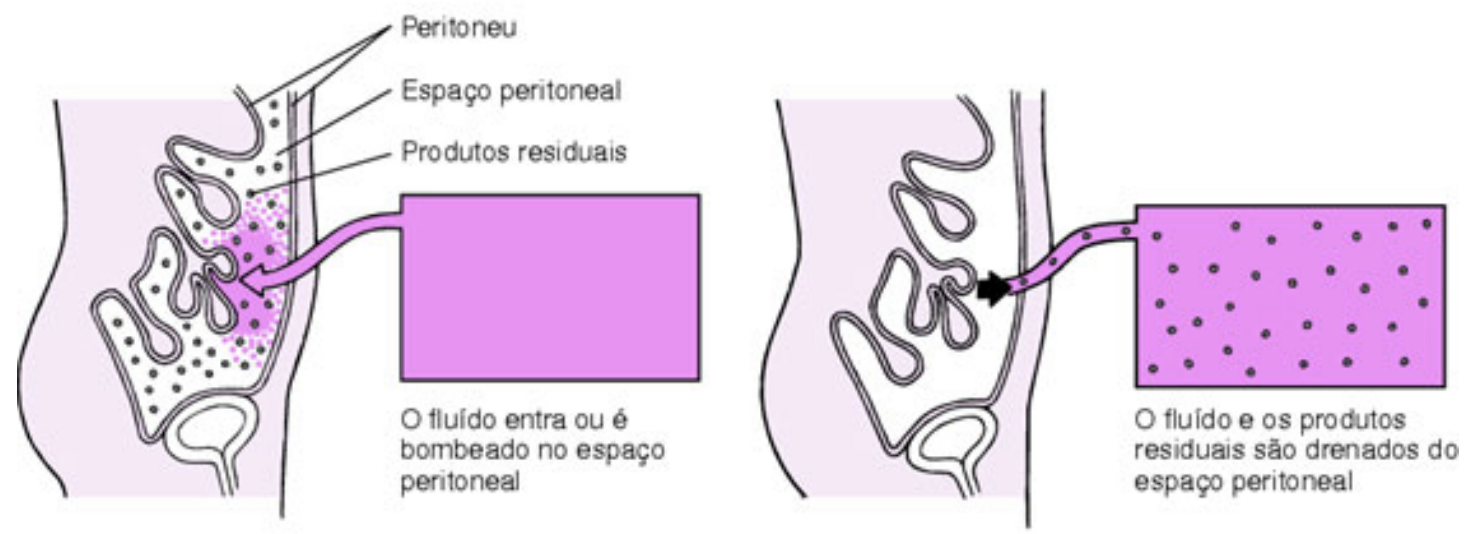

Fonte: http://www.manualmerck.net/images/p_628.gif. 
O cateter é permanente e indolor, implantado por meio de uma pequena cirurgia no abdômen. A solução de diálise é infundida e permanece por um determinado tempo na cavidade peritoneal, e depois drenada. A solução entra em contato com o sangue e isso permite que as substâncias que estão acumuladas no sangue como ureia, creatinina e potássio sejam removidas, bem como o excesso de líquido que não está sendo eliminado pelo rim. (SBN, 2015)

Uma outra opção de diálise é a hemodiálise (HD), o tratamento dialítico mais utilizado na atualidade (Sesso, 2010). Segundo o Censo da Sociedade Brasileira de Nefrologia de 2013, um total de 100.397 pacientes foram submetidos a um tratamento dialítico, sendo 90,8\% destes em HD. A maioria dos pacientes está nas regiões Sul e Sudeste, do sexo masculino (58\%) e na faixa etária dos 19 a 64 anos $(62,6 \%)$.

A HD é um processo que remove solutos acumulados em pacientes com perda total, ou quase total, da função renal. Ocorre pela difusão do soluto do sangue em uma solução salina fisiológica que é separada do sangue por uma fina membrana permeável, o principal componente da diálise (National Kidney Foundation, 2006). Apesar dos benefícios da HD, as condições impostas pela doença e pelo próprio tratamento dialítico resultam em uma série de alterações orgânicas, com complicações agudas, crônicas e nutricionais (Boxall; Goodship, 2008). Os indivíduos submetidos à HD apresentam significante prevalência de desnutrição, que pode variar de leve a grave (Nunes et al., 2008).

\subsection{AVALIAÇÃO NUTRICIONAL NA DOENÇA RENAL CRÔNICA}

A terapia nutricional é um componente integral da assistência ao paciente com DRC em estágio final. O cuidado nutricional é multifacetado e inclui não somente a educação nutricional, mas também a avaliação nutricional e monitoramento, dessa população (Fuchs, 2008).

A desnutrição energético-proteica (DEP) pode ocorrer em 13 a 51\% dos pacientes em tratamento de HD. Essa elevada prevalência de DEP é de grande preocupação por ser um importante preditor de morbimortalidade; além de ser comum nos pacientes em HD. Sua causa é multifatorial e inclui ingestão alimentar deficiente, distúrbios hormonais e gastrointestinais, restrições dietéticas rigorosas, uso de medicamentos que podem influenciar na absorção de nutrientes, diálise insuficiente e presença constante de 
comorbidades. Além disso, a uremia, a acidose metabólica e o procedimento de HD, per se, são hipercatabólicos, associados ao aumento da proteólise muscular e perdas de nutrientes no dialisato (Martins, 2008).

A DRC é muitas vezes acompanhada por albuminúria, reduções da albumina e préalbumina séricas e progressiva perda de tecido adiposo e muscular, provavelmente devido à inadequada ingestão de macronutrientes, inflamação, acidose metabólica, redução da atividade física, ou uma combinação destes processos (KDIGO, 2012; Riella; Martins, 2001).

A prevalência de deficiência proteica em estudos clínicos com pacientes em HD varia de $10 \%$ a $50 \%$. Essa variabilidade provavelmente reflete não só as diferenças populacionais, mas também os meios usados para o diagnóstico da mesma (Boxall; Goodship, 2008). Contudo, não há um marcador isolado que seja capaz de avaliar o estado nutricional de pacientes com DRC, em razão das diversas anormalidades inerentes à própria enfermidade. Recentemente, tem-se dado ênfase à avaliação subjetiva global (ASG), pois é um método simples, de baixo-custo e validado para avaliação do estado nutricional nessa população (Avesani, 2010).

Além da avaliação subjetiva global (ASG), rotineiramente, costuma-se avaliar o consumo de nutrientes, principalmente pelo registro de 3 dias ou pelo recordatório alimentar de 24 horas; a reserva de massa muscular e adiposa por antropometria ou bioimpedância elétrica e de marcadores bioquímicos pela albumina plasmática (Avesani, 2010; Kalantar-Zadeh et al., 1999; Johansen et al., 2004).

Pesquisadores renomados dessa área acreditam que seja necessário empregar em conjunto, vários parâmetros para avaliar de forma adequada a condição nutricional dessa população, de forma a contornar as limitações que cada um desses métodos apresenta quando empregados isoladamente. Apesar de todo o esforço em se aproximar do diagnóstico nutricional preciso, faltava ainda uma normatização dos parâmetros nutricionais a serem aplicados nos pacientes portadores de DRC. Nesse sentido, o Comitê da International Society of Renal Nutrition and Metabolism (2008) propôs recentemente um painel com um conjunto de indicadores nutricionais que devem ser usados para identificar o paciente com DRC portador de DEP, em que pacientes que apresentem um item de pelo menos três dos quatro critérios propostos apresentados no Quadro 1 são classificados com desnutrição energético-protéica (Avesani, 2010; Fouque et al., 2008). 
Quadro 1 - Critérios propostos pelo comitê da International Society of Renal Nutrition and Metabolism para classificar a DEP de pacientes com DRC. ${ }^{10}$

Peso e gordura corporal (massa corporal)

IMC $<23 \mathrm{~kg} / \mathrm{m}^{2}$;

Percentual de gordura corporal $<10 \%$;

Perda de peso não intencional de 5\% em 3 meses ou de 10\% em 6 meses.*

\section{Massa muscular}

Circunferência Muscular do Braço: redução > 10\% em relação ao percentil 50th do NHANES II;

Redução de massa muscular de 5\% em 3 meses ou de 10\% em 6 meses.*

Parâmetros bioquímicos

Albumina sérica $<3,8 \mathrm{~g} / \mathrm{dL}$ (método: verde de bromocresol);

Colesterol sérico $<100 \mathrm{mg} / \mathrm{dL}$

Pré-albumina sérica (transtiretina) $<30 \mathrm{mg} / \mathrm{mL}$ *

\section{Consumo Alimentar}

Redução não intencional da ingestão protéica. Valores abaixo de $0,8 \mathrm{~g} / \mathrm{kg} / \mathrm{dia}$ por 2 meses em pacientes em diálise;*

Redução não intencional da ingestão energética. Valores abaixo de $25 \mathrm{kcal} / \mathrm{kg} /$ dia por 2 meses.*

IMC: índice de massa corporal *: critérios não considerados para o diagnóstico de DEP neste estudo, uma vez que os mesmos não foram avaliados na coleta de dados. Para o critério de ingestão alimentar, foi considerada a avaliação realizada em um momento.

Fonte: Kidney Int 2008.

A albumina sérica é o marcador bioquímico mais comumente utilizado (Yeun; Kaysen, 1998; Kubrusly et al., 2012), devido à facilidade de sua medição e à sua associação com eventos clínicos nessa população (Cabral et al., 2005). Vários estudos têm mostrado forte correlação entre os baixos níveis de albumina e o aumento do risco de morbidade (Herselman et al., 2010). Outros autores sugerem que a albumina seja utilizada como um marcador do estado de hiper-hidratação e de inflamação, e, não do estado nutricional; e questionam se o estado nutricional e o risco de mortalidade seriam melhor avaliados por meio da albumina pós-HD (Kubrusly et al., 2012; Jones et al., 2002; Wapensky et al., 2004).

As diretrizes americanas Kidney Disease Outcomes Quality Initiative (KDOQI) recomendam que o nível de albumina deva ser dosado no período pré-dialítico, porém não há justificativa para a escolha desse período de coleta. Assim sendo, a hipoalbuminemia causada por hemodiluição não é comumente considerada na prática clínica (Combe et al., 2004; Kubrusly et al., 2012).

Segundo Martins (2001), na avaliação nutricional, é essencial certificar-se da adequacidade do procedimento dialítico. No início dos anos 70 , a adequacidade dialítica 
baseava-se em uma série de parâmetros clínicos e laboratoriais (Bower et al., 1971). O conceito de quantificação da diálise, baseado no modelo de cinética da ureia, foi introduzido por Gotch e Sargent, no final da década de 70 (Gotch; Sargent, 1985). A ureia foi considerada representante das toxinas urêmicas e permitiu quantificar a eficácia da diálise, a ingestão proteica e a toxicidade da uremia. O mecanismo pelo qual a diálise controla a ureia plasmática em um determinado indivíduo pode ser quantificado a partir de um clearance total de ureia prescrito, o qual é dado pelo clearance do dialisador $(\mathrm{K}$, $\mathrm{ml} /$ minuto) e o tempo de tratamento ( $\mathrm{t}$, minutos). Esse parâmetro pode ser generalizado pela normalização do volume de distribuição da ureia $(\mathrm{V}, \mathrm{ml}) \mathrm{em} \mathrm{Kt} / \mathrm{V}$, um índice que descreve a fração do clearance da água total.

Os maiores determinantes da morbidade e mortalidade em HD são o estado nutricional dos pacientes e a adequação da diálise. Provavelmente existe uma inter-relação significativa entre esses dois fatores, pois os pacientes bem dialisados apresentam maior bem-estar geral e, consequentemente, melhor ingestão alimentar. A diálise inadequada pode resultar em um estado urêmico, conduzindo a náuseas, vômitos e anorexia. No paciente subdialisado, a anorexia, com consequente redução da ingestão proteica, pode resultar em menor formação de ureia, refletida em seus níveis séricos. Os níveis baixos de ureia sérica podem dar a falsa impressão de que a diálise está adequada. Portanto, não é fácil delinear a causa e o efeito com relação ao controle inadequado da uremia e à desnutrição nesses pacientes (Martins, 2001).

A antropometria é uma das ferramentas que compõem as medidas corporais e é, também, a parte essencial da avaliação do EN. O efeito da nutrição no crescimento e no desenvolvimento humano torna indispensável as medidas de peso e das dimensões do corpo, exigindo avaliação rigorosa através de métodos padronizados para o diagnóstico e tratamento dos problemas nutricionais (Martins, 2008).

Evidências de desnutrição em pacientes com DRC incluem redução das medidas de peso corpóreo, prega cutânea triciptal (PCT) e circunferência muscular do braço (CMB) (Young et al., 1991; Stefanelli et al., 2010). Estudos da composição corporal em pacientes urêmicos revelam uma redução do tecido muscular e adiposo. Cuppari et al (1989) ao estudarem valores de PCT e CMB em pacientes hemodialisados, relataram uma importante perda de massa de gordura nas mulheres e de massa muscular nos homens. Da mesma forma, em um estudo sobre antropometria, GeYQ et al (1998) concluíram que os pacientes em terapia hemodialítica tiveram medidas de peso, PCT, CMB significativamente diminuídas em comparação ao grupo controle (pessoas saudáveis) (Stefanelli et al., 2010). 
Um estudo realizado na Califórnia, em 2000, verificou que as medidas da composição corporal tendem a ser menores após manutenção de 2 anos de tratamento dialítico, concluindo que a terapia dialítica prolongada está associada com um significativo declínio de todos os parâmetros de avaliação nutricional, e que a doença renal em estágio terminal é caracterizada como uma síndrome capaz de definhar seus portadores (Stefanelli et al., 2010; Chertow et al., 2000).

Outra medida importante é a avaliação da distribuição de gordura corpórea. Estudos epidemiológicos utilizam, desde a década de 70, a relação cintura-quadril (RCQ), por sugerirem associação direta entre a gordura abdominal com as doenças crônicas e doenças cardiovasculares (Martins, 2001).

O uso de um marcador de adiposidade central poderia auxiliar na identificação dos riscos associados às complicações metabólicas e cardiovasculares que acometem com frequência os pacientes portadores de DRC. Recentemente, o método da circunferência da cintura foi validado em 123 pacientes em tratamento conservador (Sanches FM, Avesani CM, Kamimura MA et al., 2008). Neste estudo, além da forte correlação com a gordura visceral medida pela tomografia computadorizada, a circunferência da cintura foi capaz de detectar os fatores de risco cardiovascular de forma similar à gordura visceral. Além disso, a circunferência da cintura tem-se mostrado altamente reprodutível para avaliações intra e interobservador e capaz de detectar mudanças na gordura visceral nos pacientes com DRC (Oliveira, 2008). Porém, os pontos de corte para a medida da circunferência da cintura para esta população ainda não foram definidos. (Cuppari; Kaminura, 2009).

Até o momento, a maioria das publicações sobre nutrição, em especial para o paciente com DRC em HD, abrange populações locais ou regionais e amostras com número reduzido de participantes (Cabral et al., 2005; Ribeiro et al., 2011). O registro de dados multicêntricos (várias clínicas de hemodiálise de diferentes localidades) de pacientes crônicos pode contribuir para o desenvolvimento de condutas clínicas e intervenção nutricional envolvidas no tratamento e no estabelecimento de uma melhor assistência (Sesso et al., 2008).

Para o paciente que inicia a HD é importante o estabelecimento da classificação do EN, assim como o diagnóstico nutricional (Zambon et al., 2001; Kamimura et al., 2004), pois a desnutrição energética proteica na HD é um fator de risco de morbimortalidade (Acchiardo; Moore; Latour, 1983).

Em virtude da elevada prevalência de distúrbios nutricionais nessa população e sua correlação com o prognóstico clínico torna-se fundamental o diagnóstico de nutrição, por 
meio de indicadores antropométricos, dos pacientes submetidos em tratamento hemodialítico (Stefanelli et al., 2010). 


\section{JUSTIFICATIVA}

Para compreender a DRC, importante epidemia deste século, é necessário integrá-la à abordagem das doenças crônicas como diabetes mellitus (DM) e hipertensão arterial sistêmica (HAS) e ao aumento global da expectativa de vida da população. (Levey, et al., 2007). A maioria dos portadores de DRC vai a óbito por doença cardiovascular ou para uma das modalidades de TRS, como a HD, a diálise peritoneal (DP) e o transplante renal.

No Brasil, houve um aumento da prevalência de usuários em programas de diálise, segundo o Censo da Sociedade Brasileira de Nefrologia (SBN, 2013). A incidência anual estimada de doentes em TRS é de $8 \%$ e aproximadamente $90 \%$ desses pacientes ingressam em programa de HD, estando $85 \%$ deles em unidades conveniadas do Sistema Único de Saúde - SUS (Medeiros, 2008).

A desnutrição energética-proteica (DEP) é um dos principais fatores que afetam adversamente o prognóstico do paciente renal crônico e tem sido associada ao aumento da morbidade e mortalidade nessa população de pacientes. (Oliveira, et al., 2009; Lowrie, 1990; Owen, 1993)

A fisiopatologia da DEP em pacientes renais é complexa e envolve um grande número de fatores, contribuindo para a anorexia e o catabolismo. Assim, a ingestão alimentar deficiente, as graves restrições na dieta, os distúrbios hormonais e gastrointestinais, a acidose metabólica, os medicamentos que interferem na absorção de alimentos, as doenças intercorrentes, a perda de nutrientes durante o tratamento dialítico e a diálise inadequada podem assim assumir um papel central em relação à fisiopatologia da DEP (Bergström, 1995; Guarnieri; Antonione; Biolo, 2003; Cabral; Diniz; Arruda IKG, 2005).

Portanto, a caracterização do perfil da população em HD e o diagnóstico de nutrição podem reduzir o risco de infecções e outras complicações, bem como a morbimortalidade desses pacientes.

Nesse sentido, o presente trabalho tem como objetivo caracterizar o perfil nutricional de portadores de DRC em HD. 


\section{OBJETIVOS}

\subsection{OBJETIVO GERAL}

Descrever o perfil nutricional de portadores de Doença Renal Crônica submetidos à tratamento hemodialítico.

\subsection{OBJETIVOS ESPECÍFICOS}

$\checkmark$ Identificar o perfil sócio demográfico da população de nefropatas em hemodiálise;

$\checkmark$ Analisar o estado nutricional da população em estudo. 


\title{
4. PUBLICAÇÃO
}

\section{PERFIL NUTRICIONAL DE PORTADORES DE INSUFICIENCIA RENAL CRÔNICA EM TRATAMENTO HEMODIALÍTICO}

\author{
AUTORES: COSTA, LG ${ }^{1}$; BOUSQUET-SANTOS ${ }^{2}, \mathrm{~K}$; ESCALDA ${ }^{3}$, P. \\ ${ }^{1}$ Nutricionista e Mestranda no Programa de Pós Graduação em Ciências e Tecnologias em Saúde - \\ Universidade de Brasília/Faculdade de Ceilândia (UnB/FCE) - Brasília/DF - Brasil \\ ${ }^{2,3}$ Programa de Pós Graduação em Ciências e Tecnologias em Saúde - Universidade de Brasília/Faculdade de \\ Ceilândia (UnB/FCE) - Brasília/DF - Brasil
}

\section{RESUMO}

Este artigo descreve o perfil nutricional de portadores de doença renal crônica (DRC) em hemodiálise (HD). MÉTODOS: Foram coletados dados demográficos, sociais, econômicos e epidemiológicos, por meio de questionário, em adultos $\geq 18$ anos, com mais de 90 dias de HD. Foram mensurados peso, altura, circunferências do braço (CB), cintura (CC) e prega cutânea tricipital (PCT). Foram utilizados parâmetros do Comitê da International Society of Renal Nutrition and Metabolism. A análise estatística utilizou os testes de KolmogorovSmirnov e Shapiro-Wilk (distribuição normal), T de Student ou Mann-Whitney para dados paramétricos e não paramétricos, respectivamente, e Qui-quadrado ou Fisher, para as variáveis categóricas. RESULTADOS: Foram avaliados 96 pacientes de 5 Centros de HD no Distrito Federal, sendo 57\% do sexo masculino e média de idade de 54 anos. Observouse que $54 \%$ eram pardos, $21 \%$ brancos. As causas da DRC foram atribuídas à Hipertensão Arterial Sistêmica (HAS) (44\%), seguida de Diabetes Mellitus (DM) (27\%). Apenas 14\% dos pacientes apresentavam HAS e DM. A albumina sérica foi de $3,8 \mathrm{mg} / \mathrm{dl}( \pm 0,4)$, superior nos homens. Entre as mulheres, 43\% apresentaram IMC menor que $23 \mathrm{~kg} / \mathrm{m}^{2} ; 50 \%$ apresentaram uma diminuição da CMB superior a 10\%. Para a albumina, 32 pacientes apresentaram um valor inferior a 3,8 mg/dL. Quando os parâmetros foram considerados em conjunto, 14 pacientes apresentaram desnutrição proteico-energética. Encontrou-se relação positiva entre albumina e CB, CMB, AMB e AMBSO. CONCLUSÃO: A correlação positiva e significativa entre albumina, $\mathrm{CB}, \mathrm{CMB}, \mathrm{AMB}$ e AMBSO reforçam a importância da análise do perfil nutricional de pacientes nefropatas para a prevenção da desnutrição.

Palavras- chave: doença renal crônica, hemodiálise, estado nutricional 


\section{ABSTRACT}

The major purpose of the present master thesis was to describe the nutritional profile of patients with Chronic Kidney Disease (CKD) undergoing hemodialysis (HD). CKD is characterized by failure of renal function, associated with changes in electrolyte balance and acid-base, hormonal and nutritional disorders. Hemodialysis (HD) is the most widely used dialysis today. Nutritional assessment of CRF patients on hemodialysis helps to identify risk factors for malnutrition. METHODS: Demographic, social, economic and epidemiological data were acquired to describe the profile of the population in HD and analyze their nutritional status. The research population was composed by adults $\geq 18$ years, with more than 3 months of hemodialysis. Questionnaires were used as socioeconomic data collection instrument. Serum albumin values and Kt/V were obtained from patient charts with the earliest date of anthropometric measurements. After hemodialysis session, anthropometric measurements were obtained: weight and height; arm (AC) and waist circumferences (WC) and triceps skinfold (TSF). The following parameters proposed by the International Society of Renal Nutrition and Metabolism were used for determination of patients with protein-energy malnutrition: serum albumin $<3.8 \mathrm{~g} / \mathrm{dL}$ and / or BMI $<23 \mathrm{~kg} / \mathrm{m} 2$ and / or arm muscle circumference (AMC) with reduction of $>10 \%$ relative to the 50th percentile of the NHANES II. Patients who had normal values for the three parameters simultaneously were classified as adequate nutritional status. For statistical analysis, the Kolmogorov-Smirnov and Shapiro-Wilk were applied to assess whether the data had normal distribution. We used the t-test of Student or Mann-Whitney test for parametric and non-parametric data, respectively, and to compare gender related data. For categorical variables we used the chi-square test and Fisher's exact test. The Pearson correlation test was used to assess the relationship between variables. A p value $<0.05$ was considered statistically significant. RESULTS: From a total of 96 patients in five different HD centers in the Federal District, there were 57\% male, 43\% female and the mean age was $54 \pm 15$ years. It was observed that $54 \%$ of patients were brown, $21 \%$ white, and $18 \%$ black. $52 \%$ were born in the Northeast region, in the Midwest $(30 \%)$ and Southeast (14\%) regions respectively. The causes of chronic renal failure were attributed to systemic hypertension (44\%), followed by diabetes mellitus (27\%), glomerulonephritis $(9 \%)$ or other disorders (19\%), highlighting lupus erythematosus (SLE) and bladder neurogenic as other causes. Only 14\% of those patients had comorbidities (hypertension 
and diabetes together). The value of serum albumin of the patients was $3.8 \pm 0.4 \mathrm{mg} / \mathrm{dL}$, being higher in men when compared to women $(3,9 \pm 0,4$ vs 3,7 $\pm 0,4 \mathrm{mg} / \mathrm{dL}$ respectively; $\mathrm{P}=0.006)$. For the evaluation of protein-calorie malnutrition the International Society of Renal Nutrition and Metabolism parameters were used. Regarding BMI of 96 evaluable patients, 41 patients $\left(43 \%\right.$; 18 women) had a BMI less than $23 \mathrm{~kg} / \mathrm{m}^{2} .48$ patients $(50 \%$; 12 women; $\mathrm{P}<0.05$ vs men) had a reduction in their $\mathrm{AMC}$, more than $10 \%$ compared to the 50th percentile. 32 patients $(33 \%$; 18 women) had albumin value lower than $3.8 \mathrm{mg} / \mathrm{dL}$. When all three parameters were considered together, 14 patients were identified with $(15 \%$; $57 \pm 14 ; 7$ females) protein-energy malnutrition characteristics. We found a positive relationship between albumin and AC, AMC, MAA and MAA boneless. CONCLUSION: The thesis concluded upon a positive and significant correlation between albumin and AC, AMC, MAA and MAA boneless that reinforces the importance of the nutritional profile of nephropathic patients for preventing malnutrition. Hypertension and diabetes are present in $1 / 4$ of the population studied.

KEYWORDS: chronic kidney disease, hemodialysis, nutritional status. 


\section{INTRODUÇÃO}

A doença renal crônica (DRC) constitui, atualmente, um problema de Saúde Pública. Trata-se da perda lenta, progressiva e irreversível das funções renais. ${ }^{1,2,3}$

As causas da DRC vão desde doenças primárias dos rins, às doenças sistêmicas e doenças do trato urinário. A Nefropatia Diabética, Hipertensão Arterial e Glomerulonefrite Primária são as causas mais comuns da Doença Renal Terminal (DRCT) ${ }^{4,5,6}$

$\mathrm{O}$ paciente com DRC apresenta alterações sistêmicas devido às múltiplas funções renais afetadas, doenças de base sistêmicas e às próprias complicações referentes à doença renal. $^{7}$

Nas fases iniciais da DRC, quando as manifestações clínicas e laboratoriais são mínimas ou ausentes, o diagnóstico pode ser sugerido pela associação de manifestações inespecíficas como fadiga, anorexia, emagrecimento, prurido, náusea ou hemólise, hipertensão, poliúria, nictúria, hematúria ou edema.

Assim, para o tratamento, faz-se necessário desde a psicoterapia, o direcionamento nutricional, o controle das doenças primárias, a correção dos distúrbios metabólicos, orientações adequadas sobre a doença, tratamento e autocuidado; envolvendo equipe multidisciplinar, até a adoção de uma terapia renal substitutiva. ${ }^{8,9}$

A hemodiálise (HD) é o tratamento dialítico mais utilizado na atualidade. O censo da Sociedade Brasileira de Nefrologia (SBN), realizado em 2013, apresentou um total de 100.397 pacientes foram submetidos a um tratamento dialítico, sendo 90,8\% destes em HD. A maioria dos pacientes está nas regiões Sul e Sudeste, do sexo masculino (58\%) e na faixa etária dos 19 a 64 anos $(62,6 \%)$

Apesar dos benefícios da HD, as condições impostas pela doença e pelo próprio tratamento dialítico resultam em uma série de alterações orgânicas, com complicações agudas, crônicas e nutricionais. Os indivíduos submetidos à diálise apresentam significante prevalência de desnutrição, que pode variar de leve a grave. ${ }^{13}$

Segundo Martins (2001), os maiores determinantes da morbidade e mortalidade em HD são o estado nutricional dos pacientes e a adequacidade da diálise.

A desnutrição energético-proteica (DEP) pode ocorrer em 13 a 51\% dos pacientes em tratamento de hemodiálise. Essa elevada prevalência de DEP é de grande preocupação por ser um importante preditor de morbimortalidade; além de ser comum nos pacientes em Hemodiálise. Sua causa é multifatorial e inclui ingestão alimentar deficiente, distúrbios 
hormonais e gastrointestinais, restrições dietéticas rigorosas, uso de medicamentos que podem influenciar na absorção de nutrientes, diálise insuficiente e presença constante de comorbidades. Além disso, a uremia, a acidose metabólica e o procedimento de HD, per se, são hipercatabólicos, associados ao aumento da proteólise muscular e perdas de nutrientes no dialisato. $^{14}$

A literatura demonstra altas taxas de morbidade e mortalidade em HD, sobretudo naqueles pacientes com desnutrição. Portanto a detecção e o tratamento precoce do déficit nutricional podem reduzir o risco de infecções, outras complicações e a morte desses pacientes.

O estado nutricional (EN) constitui importante fator de risco na evolução clínica dessa população. Assim, é fundamental a classificação do EN desses pacientes, tanto para prevenir má nutrição; quanto para indicar a intervenção adequada nos pacientes desnutridos.

A avaliação nutricional possibilita identificar as causas de risco ou deterioração do EN, auxiliando na terapia específica e na determinação das necessidades de cada nutriente. $^{15}$

A antropometria é uma das ferramentas que compõem as medidas corporais e é também a parte essencial da avaliação do EN. Os registros da ingestão alimentar e de nutrientes são amplamente utilizados em pesquisas de grupos populacionais. ${ }^{15}$

Até o momento, a maioria das publicações sobre nutrição, em especial para o paciente com DRC em HD, abrange populações locais ou regionais e amostras com número reduzido de participantes. O registro de dados multicêntricos (várias clínicas de hemodiálise de diferentes localidades) de pacientes crônicos pode contribuir para o desenvolvimento de condutas clínicas e intervenção nutricional envolvidas no tratamento e no estabelecimento de uma melhor assistência. ${ }^{16 .}$

Nesse sentido, o presente trabalho teve como objetivo descrever o perfil da população e o estado nutricional de portadores de DRC em tratamento Hemodialítico no Distrito Federal.

\section{MÉTODOS}

Trata-se de um estudo descritivo, no qual a população pesquisada incluiu pacientes cadastrados em cinco Centros de Hemodiálise registrados na Sociedade Brasileira de 
Nefrologia e no Cadastro Nacional de Estabelecimentos de Saúde (CNES) do Distrito Federal. Foram incluídos no estudo pacientes portadores de DRC em tratamento hemodialítico há mais de três meses (tempo necessário para estabilização do paciente ao tratamento referido), de ambos os sexos, adultos maiores de 18 anos, com condições clínicas e/ou psicológicas que permitissem sua participação no estudo.

Como instrumento de coleta de dados socioeconômicos foi utilizado um questionário, aplicado pelo pesquisador. Valores de albumina sérica e Kt/V foram obtidos no prontuário com data mais próxima da avaliação antropométrica, considerando o método de verde de bromocresol para dosagem de albumina e a fórmula do Daugirdas II para o cálculo do Kt/V. Após a sessão de hemodiálise foram obtidas as seguintes medidas antropométricas: peso e altura (Filizola, São Paulo, Brasil); circunferências do braço (CB) e cintura (CC) utilizando fita não-elástica e prega cutânea tricipital (PCT) (Adipômetro Clínico Sanny®, Brasil). No momento da avaliação, os participantes foram orientados a usar roupas leves e ficarem descalços e centralizados, eretos, braços soltos ao longo do corpo e olhar na linha do horizonte, conforme Plano de Frankfurt (Chumlea, 1985). Todas as medidas foram realizadas pelo mesmo avaliador. Para determinação da altura em pacientes impossibilitados de ficarem de pé foi utilizado o valor estimado por meio da extensão dos braços, que é medida entre o centro do peito (esterno) até o final do dedo médio da mão. Utilizou-se a seguinte fórmula: Altura = distância do braço $(\mathrm{cm}) \times 2,0$ (Lohman, 1988). A circunferência muscular do braço (CMB) foi calculada a partir da fórmula $\mathrm{CMB}(\mathrm{cm})=\mathrm{CB}(\mathrm{cm})$ - $(\mathrm{PCT}$ em $\mathrm{mm} \times 0,314)$ e os resultados foram classificados por Frisancho, (1981). A área muscular do braço (AMB) e área muscular do braço sem osso (AMBSO) foram calculadas com o auxílio do programa de Apoio à Nutrição NutWin Versão 1.5.2.51/2005 e os resultados também comparados por Frisancho (1981).

Os seguintes parâmetros propostos pela International Society of Renal Nutrition and Metabolism foram utilizados para determinação de pacientes com desnutrição energéticoproteica: albumina sérica $<3,8 \mathrm{~g} / \mathrm{dL}$ e/ou IMC $<23 \mathrm{~kg} / \mathrm{m}^{2}$ e/ou circunferência muscular do braço com redução $>10 \%$ em relação ao percentil 50 do NHANES II. Foram classificados com EN adequado aqueles pacientes que apresentassem valores de normalidade para os três parâmetros concomitantemente.

Análise Estatística: Inicialmente foram aplicados os testes de Kolmogorov-Smirnov e Shapiro-Wilk para avaliar se os dados apresentavam distribuição normal. Na comparação dos resultados entre gêneros foi utilizado o teste-T de Student ou Mann-Whitney para dados paramétricos e não paramétricos, respectivamente. Para as variáveis categóricas foi 
utilizado o teste Qui-quadrado ou teste exato de Fisher, quando apropriado. O teste de correlação de Pearson foi utilizado para avaliar a relação entre variáveis. Os dados foram analisados no programa Prism 5 for Windows, versão 5.04. O valor de $\mathrm{p}<0,05$ foi considerado estatisticamente significativo.

O estudo foi aprovado pelo Comitê de Ética em Pesquisa da Universidade de Brasília - UnB (nº 30679314.5.0000.0030) e pelo Comitê de Ética da Fundação de Ensino e Pesquisa em Ciências da Saúde - FEPECS do Distrito Federal ( $\mathrm{n}^{\circ}$ 31752614.7.0000.5553). Todos os pacientes foram esclarecidos sobre os procedimentos do estudo e assinaram o Termo de Consentimento Livre e Esclarecido.

\section{RESULTADOS}

Foram avaliados 96 pacientes de cinco Centros de HD no Distrito Federal, 57\% do sexo masculino, $43 \%$ do sexo feminino e a média de idade foi de $54 \pm 15$ anos. Em relação à distribuição dos pacientes por faixa etária, 38\% era maior de 60 anos, $32 \%$ entre 50 e 59 anos, $9 \%$ entre 40 e 49 anos, $15 \%$ entre 30 e 39 anos e apenas $6 \%$ entre 20 e 29 anos.

Quando analisadas as características sociais, observou-se que 54\% dos pacientes eram pardos, $21 \%$ brancos, $18 \%$ negros, $4 \%$ de indígenas e 3\% não informaram esta questão. Quanto à naturalidade, 52\% eram da região Nordeste, seguidos das regiões CentroOeste $(30 \%)$ e Sudeste $(14 \%)$, respectivamente. Em relação à escolaridade, $35 \%$ dos avaliados cursaram o ensino fundamental incompleto, $17 \%$ o ensino médio completo, seguido de $14 \%$ que cursaram o ensino médio incompleto e eram analfabetos. Apenas 3\% dos pacientes cursaram o ensino superior completo. A maioria dos pacientes (79\%) relatou receber de 1 a 2 salários-mínimos por mês. Para frequentar as sessões de HD, 46\% utilizava transporte próprio, $26 \%$ transporte público e $28 \%$ transporte sanitário do Governo do Distrito Federal (GDF).

Em relação aos resultados clínicos, as principais causas da DRC foram atribuídas à Hipertensão Arterial Sistêmica (44\%), seguida de Diabetes Mellitus (27\%), glomerulonefrites (9\%) ou outras patologias (19\%), destacando-se Lúpus Eritematoso Sistêmico (LES) e bexiga neurogênica como outras causas. Quando agrupado Hipertensão e Diabetes observou-se que apenas 14\% dos pacientes apresentavam estas comorbidades. Em relação à percepção do seu estado de saúde (muito bom, bom, regular ou ruim), 81\% da população estudada classificou como regular ou ruim. 
A média de tempo em HD apresentada pelo grupo foi de $46 \pm 47$ meses, sendo a fistula arteriovenosa o principal tipo de acesso utilizado para o procedimento $(83 \%$ dos pacientes).

O valor de albumina sérica dos pacientes avaliados foi de $3,8 \pm 0,4 \mathrm{mg} / \mathrm{dL}$, sendo superior nos homens em comparação às mulheres $(3,9 \pm 0,4$ vs $3,7 \pm 0,4 \mathrm{mg} / \mathrm{dL}$ respectivamente; $P=0,006)$. Em relação ao $\mathrm{Kt} / \mathrm{V}$, dos 96 pacientes somente 58 tinham o resultado desse parâmetro disponível em prontuário e destes somente 19 possuíam Kt/V igual a 1,2, conforme as diretrizes da Sociedade Brasileira de Nefrologia (SBN).

Os resultados da avaliação antropométrica são apresentados na tabela 1.

Tabela 1: Resultado da avaliação antropométrica dos pacientes avaliados.

\begin{tabular}{|c|c|c|c|}
\hline INDICADOR & $\begin{array}{l}\text { GERAL } \\
(\mathrm{N}=96)\end{array}$ & $\begin{array}{l}\text { MASCULINO } \\
\qquad(\mathrm{N}=56)\end{array}$ & $\begin{array}{l}\text { FEMININO } \\
\qquad(\mathrm{N}=40)\end{array}$ \\
\hline $\begin{array}{l}\text { Índice de Massa Corpórea } \\
\left(\mathrm{kg} / \mathrm{m}^{2}\right)\end{array}$ & $24,5 \pm 4,8$ & $24,2 \pm 5,1$ & $24,7 \pm 4,5$ \\
\hline Circunferência do Braço (cm) & $26,3 \pm 3,6$ & $26,0 \pm 4,2$ & $26,6 \pm 3,1$ \\
\hline $\begin{array}{l}\text { Circunferência Muscular do } \\
\text { Braço (cm) }\end{array}$ & $22,7 \pm 3,0$ & $21,3 \pm 2,9$ & $23,8 \pm 2,6$ \\
\hline Área Muscular do Braço (cm) & $41,8 \pm 10,9$ & $36,6 \pm 10,0$ & $45,6 \pm 10,0$ \\
\hline $\begin{array}{l}\text { Área Muscular do Braço sem } \\
\text { osso }(\mathrm{cm})\end{array}$ & $33,3 \pm 10,3$ & $30,1 \pm 10,0$ & $35,7 \pm 10,0$ \\
\hline Prega Cutânea Triciptal (mm) & $11,6 \pm 6,0$ & $14,9 \pm 6,8$ & $9,0 \pm 3,7$ \\
\hline Circunferência Cintura (cm) & --- & $84,4 \pm 15,1$ & $91,4 \pm 12,1$ \\
\hline Circunferência Quadril (cm) & --- & $91,8 \pm 9,4$ & $92,6 \pm 9,6$ \\
\hline Relação Cintura Quadril (cm) & --- & $0,9 \pm 0,1$ & $1,0 \pm 0,1$ \\
\hline
\end{tabular}

Fonte: Próprio autor.

Para avaliação da desnutrição proteico-calórica foram utilizadas as metas da International Society of Renal Nutrition and Metabolism, que incluíram IMC, adequação de CMB e albumina sérica. Em relação ao IMC, dos 96 pacientes avaliados, 41 pacientes 
(43\%; 18 mulheres) apresentaram IMC menor que $23 \mathrm{~kg} / \mathrm{m}^{2}$. Quanto à CMB, 48 pacientes (50\%; 12 mulheres; $\mathrm{P}<0,05$ vs homens) apresentaram uma diminuição em seu valor superior a 10\% em comparação ao percentil 50. Para a albumina, 32 pacientes $(33 \%$; 18 mulheres) apresentaram um valor inferior a 3,8 $\mathrm{mg} / \mathrm{dL}$. Quando as três metas foram consideradas em conjunto, foram identificados 14 pacientes $(15 \% ; 57 \pm 14$ anos; 7 mulheres) com características de DEP.

O teste de correlação foi realizado para identificar quais dentre as variáveis nominais (variáveis dependentes) poderiam influenciar os valores de albumina sérica (variável independente). A figura abaixo demonstra a relação positiva encontrada entre albumina e $\mathrm{CB}, \mathrm{CMB}, \mathrm{AMB}$ e AMB sem osso. Todas estatisticamente significativas: $\mathrm{P}=$ 0,$0009 ; \mathrm{P}=0,0178 ; \mathrm{P}=0,0014 ; \mathrm{P}=0,0040$, respectivamente.

Figura 2: Correlações da Albumina com CB, CMB, AMB e AMB sem osso
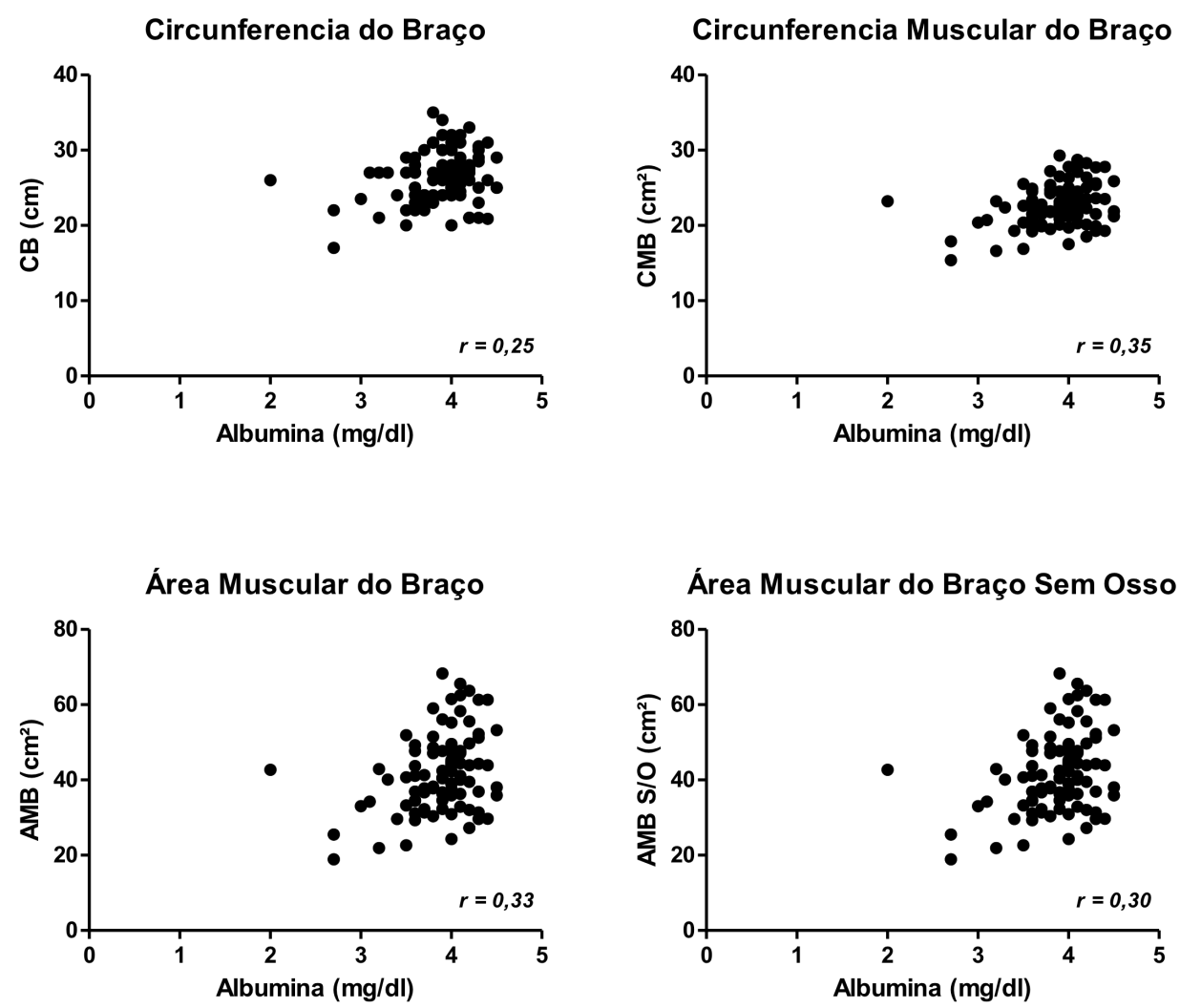

Fonte: Próprio autor. 


\section{DISCUSSÃO}

O EN dos pacientes com DRC em HD tem despertado grande interesse, justificado por sua relação direta com a morbimortalidade (Kopple, 2000). Assim sendo, a análise dos resultados obtidos nesse estudo possibilitou descrever o perfil sócio demográfico, epidemiológico e EN dos pacientes portadores de DRC em HD no Distrito Federal.

Com base nos resultados apresentados, observamos que a média da idade assemelhou-se com outros estudos nacionais, em que a média de idade variou de 49 a 51 anos; porém mostra uma população relativamente jovem, se comparado a pacientes norte americanos, cuja média de idade é de 60 anos (Lameire, 2002).

Nas cinco regiões do país, a menor média de idade de entrada em Terapia Renal Substitutiva foi observada entre pacientes residentes na região Centro-Oeste (média 51 anos) e a maior na região Sul (55 anos), que também apresentou o maior percentual de pacientes idosos (31\%). Nas cinco regiões, a maioria dos pacientes (de 60\% a 69\%) iniciou Terapia Renal Substitutiva em faixa etária intermediária (20 a 64 anos) (Cherchiglia et al, 2010).

Quando analisada a questão do tipo de transporte, os dados mostram que a organização do Sistema de Saúde no Distrito Federal em relação aos pacientes nefropatas apresenta-se desfavorável quando se trata de transporte sanitário para essa população.

Em relação à condição econômica, os dados apresentados sugerem ser um fator desfavorável (apenas 1 a $2 \mathrm{SM}$ ), levando a falta de informações e, consequentemente, uma menor procura por tratamento médico adequado, além de influenciar no autocuidado e conhecimento da patologia, seu tratamento e controle. A baixa renda mensal informada pelos pacientes pode estar vinculada aos meios de obtenção da mesma, tais como a falta do vínculo empregatício, auxílio doença, e/ou aposentadoria (Kusumoto L et al., 2008). No estudo de Cabral et al., (2005) também foi encontrado baixo nível socioeconômico em 83\% dos pacientes estudados que subsistiam com renda igual ou inferior a 2 salários-mínimos e com 40,6\% dos pacientes declarando-se sem instrução.

$\mathrm{Na}$ análise dos dados clínicos observou-se uma indisponibilidade das informações (falta de preenchimento dos prontuários analisados) como etiologia da doença, exames laboratoriais (albumina sérica) e de adequação em diálise (Kt/V). Informação necessária e de essencial importância para uma efetiva atualização de dados aos órgãos do Sistema Único de Saúde e da Sociedade Brasileira de Nefrologia; melhor adequação do tratamento e 
gestão dessas informações. Segundo as diretrizes do Kidney Outcomes Quality Initiative (KDOQI, 2002), deve-se avaliar o contexto clínico, incluindo a história pessoal, familiar, fatores ambientais, medicamentos, exame físico, medidas laboratoriais, exames de imagem e diagnósticos histopatológicos para determinar as causas da doença renal (sem graduação), utilizando métodos clínicos convencionais (atenção para diagnósticos diferenciais de hipertensão arterial e diabetes).

No que diz respeito a etiologia da DRC, os resultados encontrados assemelham-se com o estudo de Ribeiro et al., (2008), onde ao analisar a doença de base, observou-se como doença prévia principalmente, a nefroesclerose hipertensiva $(31,3 \%$,), diabetes Mellitus (25,3\%), seguido da glomerulonefrite em 24,5\% dos pacientes estudados. No Censo Brasileiro de Diálise (2012), os dados da DRC também foram hipertensão arterial (34\%) e diabetes (29\%), seguidos por glomerulonefrite crônica (13\%) e rins policísticos $(4 \%)$.

O achado de somente $14 \%$ dos pacientes apresentarem hipertensão e diabetes concomitante é um reflexo da indisponibilidade da informação, o que corrobora ao estudo de Batista et al., (2003), em que relata a inexistência dos registros de dados clínicos etiologia e exames, como albumina, evidenciando claramente a necessidade de otimização das medidas que chamam a atenção para o desconhecimento sobre as comorbidades que são encontradas na DRC em HD. Um dado que pode ser mencionado para justificar o fato de ter encontrado mais homens em tratamento hemodialítico, é que a prevalência no Brasil de HAS no sexo masculino é quase três vezes maior que no sexo feminino (Terra, 2007; Nomura et al., 1995)

Os dados sobre o acesso venoso para HD encontrados nesse estudo se aproximam similares aos do Censo Brasileiro de Diálise 2012 e de Ribeiro et al., (2008), em que a maioria dos pacientes em HD tinham fistula arteriovenosa (FAV) como acesso principal.

Dentre os diversos parâmetros bioquímicos empregados para avaliação do EN, a albumina sérica tem sido a mais utilizada, devido à sua estreita associação com taxas de mortalidade em pacientes renais (Kaysen; Eiserich, 2004). No presente estudo, a média do valor de albumina sérica ficou dentro da normalidade; sugerindo que a albumina não se comportou como um marcador de desnutrição. No estudo de Valenzuela RGV et al., 2003; e Blumenkrantz, et al., 1980, também foi observada a baixa sensibilidade da albumina sérica na detecção da desnutrição. Como a albumina é uma proteína de fase aguda, com síntese hepática reduzida em quadros inflamatórios, não se sabe ainda se sua associação com as taxas de morbimortalidade seja decorrente da DEP ou de inflamação ou, ainda, da 
coesão de ambas as condições. Sendo assim, sugere-se de que o uso isolado da albumina sérica como marcador de desnutrição nessa população possa não ser adequado.

Vários estudos demonstram correlação entre o estado nutricional e a eficiência da diálise, medida pelo Kt/V. No presente trabalho, somente 19 pacientes apresentavam valores dentro das recomendações da SBN. Como mencionado anteriormente, a falta de registros nos prontuários dos pacientes em tratamento hemodialítico foi um dos fatores que mais chamou a atenção e o registro da informação correta é de fundamental importância para adequação do tratamento e gestão das mesmas.

No que diz respeito ao IMC, vale ressaltar que ele isoladamente apresenta baixa sensibilidade em detectar a desnutrição em pacientes com DRC em HD devido a retenção hídrica comum nessa população, sendo necessária a associação com outros indicadores (Santos, et al., 2006; Valenzuela, et al., 2003 e Stefanelli, et al., 2010).

Evidências de desnutrição em pacientes com DRC incluem redução das medidas de peso corpóreo, prega cutânea triciptal (PCT) e circunferência muscular do braço (CMB) (Young et al., 1991; Stefanelli et al., 2010). Estudos da composição corporal em pacientes urêmicos revelam uma redução do tecido muscular e adiposo. Cuppari et al (1989) ao estudarem valores de PCT e CMB em pacientes hemodialisados, relataram uma importante perda de massa de gordura nas mulheres e de massa muscular nos homens. Da mesma forma, em um estudo sobre antropometria, GeYQ et al (1998) concluíram que os pacientes em terapia hemodialítica tiveram medidas de peso, PCT, CMB significativamente diminuídas em comparação ao grupo controle (pessoas saudáveis) (Stefanelli et al., 2010).

Um estudo realizado na Califórnia em 2000, verificou que as medidas da composição corporal tendem a ser menores após manutenção de 2 anos de tratamento dialítico, concluindo que a terapia dialítica prolongada está associada com um significativo declínio de todos os parâmetros de avaliação nutricional, e que a doença renal em estágio terminal é caracterizada como uma síndrome capaz de definhar seus portadores (Stefanelli et al., 2010; Chertow et al., 2000).

Os valores de IMC, CMB e albumina sérica foram utilizados neste estudo para avaliar a presença de DEP. Os resultados assemelham-se aos encontrados no estudo de Stefanelli, et al., 2010, onde o percentual de eutrofia segundo a porcentagem de adequação dos indicadores antropométricos em relação ao percentil 50 foi de $\mathrm{CB}=29 \%, \mathrm{PCT}=12 \%$ e $\mathrm{CMB}=55 \%$.

Cabe salientar que a presente pesquisa encontrou limitações relativas a: bases de dados incompletas e/ou inacessíveis no âmbito da Secretaria de Saúde do Distrito Federal; 
falta de registro sistematizado sobre a etiologia, exames laboratoriais (albumina) e de adequação em diálise (Kt/V) nos diversos centros pesquisados; ausência de sistema de avaliação dos usuários e dos serviços prestados; baixa qualificação profissional no atendimento aos pacientes nefropatas. Identificadas essas fragilidades, sugere-se ampliar o número de grupos de pesquisa na DRC e seus tratamentos; investir na organização dos prestadores de serviços de HD no Distrito Federal; sistematizar as informações e os bancos de dados nacionais e locais, afim de viabilizar subsídios necessários a melhoria das políticas públicas de saúde no Distrito Federal.

\section{CONCLUSÃO}

Por meio deste estudo, pode-se concluir que o perfil da população estudada foi composto por homens, pardos, com média de idade de 54 anos, naturais da região do Nordeste e com renda mensal entre 1 a 2 salários-mínimos. Hipertensão e Diabetes Mellitus estão presentes em $1 / 4$ da população relativamente jovem. A desnutrição esteve presente em $43 \%$ dos pacientes avaliados. Foi encontrada uma correlação positiva entre albumina, CB, CMB, AMB e AMB sem osso.

Agradecimentos: A discente Mariana Mendes pela colaboração na coleta de dados.

\section{REFERÊNCIAS BIBLIOGRÁFICAS}

1. Carvalhares, JTA. Insuficiência Renal Crônica. In: Nóbrega, FJ. Clínica Pediátrica. Rio de Janeiro: Guanabara Koogan, 1987, 522p.

2. Wills, MR. Effects of renal failure. Clin. Biochem., 1990, 23: 55-60.

3. Ryan TP, Sloand JÁ, Winters PC, Corsetti JP, Fisher SG. Chronic kidney disease prevalence and rate of diagnosis. Am J Med., 2007, 120: 981-6. 
4. SBN (Sociedade Brasileira de Nefrologia). Censos - 2009. [citado 13 dez 2011]. Disponível em: http://www.sbn.org.br.

5. Oliveira, GTC; Andrade, EIG; Acurcio, FA. et al. Avaliação nutricional de pacientes submetidos à hemodiálise em centros de Belo Horizonte. Assoc Med Bras 2012; 58(2): 240-247.

6. Barros E, Thomé F. Prevenção de doenças renais. In: Barros E, Manfro RC, Thomé F, Gonçalves LF, colaboradores. Nefrologia: rotinas, diagnóstico e tratamento. $2^{\mathrm{a}}$ ed. Porto Alegre: Artmed; 1999: 59-61.

7. Barreto ACP, Santello, JL, Manual de Hipertensão: entre a evidência e a prática clínica. São Paulo: Lemos Editorial; 2002: 137-9.

8. Ribeiro RCHM, Oliveira GASA, Ribeiro DF, Bertolin DC, Cesarino CB, Lima LCEQ, Oliveira SM. Caracterização e etilologia da insuficiência renal crônica em unidade de nefrologia do interior do Estado de São Paulo. Acta Paul Enferm 2008; 21 (Número Especial): 207-11.

9. Porto, CC. Doenças do coração: prevenção e tratamento. Rio de Janeiro: Guanabara Koogan; 1998, 87: 453.

10. Carpenito LJ. Plano de cuidados e documentação. Porto Alegre: Artes Médicas; 1999: 61923.

11. Braunwald E. Tratado de medicina cardiovascular. 4a ed. São Paulo: Roca; 1996, 1: 881-7.

12. Schor N, Srougi M. Nefrologia, urologia clínica. 6a ed. São Paulo: Sarvier; 1998: 29-33.

13. Sesso R de C, Lopes AA, Thome FS, Lugon JR, Burdmann Ede A. Brazilian dialysis censos, 2009. J Bras Nefrol. 2010; 32: 374-8.

14. Martins, C. Avaliação do Estado Nutricional e Diagnóstico. Vol I, Nutroclínica, 2008: 43.

15. Riella, MC, Martins, C. Nutrição e o Rim. Rio de Janeiro. Guanabara Koogan; 2001.

16. Sesso R, Lopes AA, Thomé FS, Bevilacqua JL, Romão Jr JE, Lugon J. Relatório do Censo Brasileiro de Diálise. J Bras Nefrol; 2008, 30: 233-8.

17. Romão Jr JE. Doença Renal Crônica: Definição, Epidemiologia e Classificação. J Bras Nefrol; 2004, vol. XXVI, n 3, Supl 1. 
18. Cabral PC, Diniz AS, Arruda IKG. Avaliação nutricional de pacientes em hemodiálise. Rev Nutr; 2005, 18: 29-40.

19. Guarnieri G, Antonione R, Biolo G. Mechanisms of malnutrition in uremia. J Renal Nutr 2003; 13:153-7.

20. Bergström J. Why are dialysis patients malnourished? Am J Kidney Dis 1995; 26: 229-41.

21. Lima-Costa MF, Barreto, SM. Tipos de estudos epidemiológicos: conceitos básicos e aplicações na área do envelhecimento. Epidemiol. Serv. Saúde 2003, vol. 12, n.4, pp. 189201.

22. Lowrie EG, Lew NL. Death risk in hemodialysis patients: the predictive value of commonly measured variables and an evaluation of death rate differences between facilities. Am J Kidney Dis 1990; 15: 458-82.

23. Ribeiro MMC, Araújo ML, Netto MP, Cunha LM. Impacto do hábito de jantar sobre o perfil dietético de pacientes em hemodiálise. J Bras Nefrol 2011; 33: 69-77.

24. KDOQI - National Kidney Foundation (homepage). Acessado em 5/2/2013, Disponível em http://www.kidney.org/professionals/kdoqi/

25. Detsky AS, Mclaughlin JR, Baker JP, Johnston N, Whittaker S, Mendelson RA et al. What is subjective global assessment of nutritional status? J Parenter Enteral Nutr.; 1987, 11: 55 60 .

26. Blackburn, G. L.; Thornton, P. A. nutritional assessment of the hospitalized patients. Med. Clin. North Am.; 1979, 63: 1103-15.

27. Chumlea, W. C.; Roche, A. F.; Steinbaugh, M. L. Estimating stature from knee height for persons 60 to 90 years of age. Journal American Geriatric Sociation; 1985, 33: 116-120.

28. Frisancho AR. New norms of upper limb fat and muscle areas for assessment of nutritional status. Am J Clin Nutr; 1981, 34: 2540-5. 


\section{DISCUSSÃO GERAL}

A incidência de pacientes com doença renal em estágio final, tratados por terapia renal substitutiva, varia enormemente dependendo do nível de desenvolvimento do país. Nas regiões altamente desenvolvidas, como América do Norte, Europa e Japão apresentam as taxas mais elevadas de incidência de pacientes em hemodiálise. Nota-se que a questão do desenvolvimento parece influenciar a oferta de tratamento. Ou seja, não significa que existam poucos indivíduos com DRC; o que normalmente ocorre é uma oferta insuficiente de tratamento nos países em desenvolvimento.

A evolução da DRC depende da qualidade do atendimento ofertado muito antes da ocorrência da falência renal. A Sociedade Brasileira de Nefrologia chama a atenção para a necessidade do diagnóstico precoce da DRC, a pertinência do encaminhamento imediato para acompanhamento nefrológico e para a implementação de medidas que retardem a progressão da doença, assim como a correção de suas complicações e comorbidades quando instaladas (Bastos et al., 2004).

A avaliação do estado nutricional nessa população é de suma importância para adequação de medidas terapêuticas de prevenção da desnutrição. Diversos fatores contribuem para essa condição nutricional, sendo o processo inflamatório uma importante causa desse quadro (Marcen et al., 1997; Vegine et al., 2011); além da anorexia, perdas de nutrientes pelo dialisato, toxinas urêmicas, ingestão inadequada, anormalidades endócrinas, resistência a insulina entre outras.

Portanto, a importância da mensuração da composição corporal, destaca-se por ser acessível, rápida, de baixo custo e boa reprodutibilidade (Blumenkrantz et al., 1980).

Ainda que existam restrições relativas à amostragem, devido ao custo de aplicação, os resultados encontrados no presente estudo reforçam a análise de Valenzuela et al (2002) na Amazônia e de Calado et al (2007) na capital do Maranhão, principalmente no que se refere à prevalência da desnutrição, à eutrofia considerando os parâmetros de IMC e a albumina como variável a ser observada.

A presente dissertação encontrou limitações relativas a:

$\checkmark$ bases de dados incompletas e/ou inacessíveis no âmbito da Secretaria de Saúde do Distrito Federal;

$\checkmark$ falta de registro sistematizado sobre a etiologia, exames laboratoriais (albumina) e de adequação em diálise $(\mathrm{Kt} / \mathrm{V})$ nos diversos centros pesquisados; 
$\checkmark$ ausência de sistema de avaliação dos usuários e dos serviços prestados;

$\checkmark$ baixa qualificação profissional no atendimento aos pacientes nefropatas.

Identificadas essas fragilidades, sugere-se ampliar o número de grupos de pesquisa na DRC e seus tratamentos; investir na organização dos prestadores de serviços de HD no Distrito Federal; sistematizar as informações e os bancos de dados nacionais e locais, afim de viabilizar subsídios necessários a melhoria das políticas públicas de saúde no Distrito Federal. 


\section{CONCLUSÕES}

Conforme definido no objetivo geral, a presente dissertação tratou de descrever o perfil nutricional dos portadores de DRC submetidos a tratamento hemodialítico. Primeiramente constatou-se que o perfil sócio demográfico da população de nefropatas é composto, em sua maioria, por homens (57\%), entre 30 e 59 anos de idade (56\%), pardos (54\%), naturais da região nordeste e com renda mensal de 1 a 2 SM. HAS e DM foram encontrados em $1 / 4$ da população estudada.

Para avaliação da DEP foram utilizadas as metas da International Society of Renal Nutrition and Metabolism, que incluíram IMC, adequação de CMB e albumina sérica. Quando as três metas foram consideradas em conjunto, foram identificados 14 pacientes (15\%; $57 \pm 14$ anos; 7 mulheres) com características de DEP. Também encontrou-se uma correlação positiva entre albumina, $\mathrm{CB}, \mathrm{CMB}, \mathrm{AMB}$ e $\mathrm{AMB}$ sem osso. 


\section{REFERÊNCIAS BIBLIOGRÁFICAS}

1 Schmidt MI, Ducan BB et al. Doenças crônicas não-transmissíveis no Brasil: carga e desafios atuais. In: Série Saúde no Brasil www.thelancet.com, 2008.

2 Yach D, Hawkes C, Gould CL, Hofman KJ. The global burden of chronic diseases: overcoming impediments to prevention and control. JAMA, 2004; 291:2616-22. In: Atkins R. The Epidemiology of Chronic Kidney Disease. Kidney International, 2005; 67 (Supplement 94): S14-S18.

3 Cherchiglia ML. et al. Perfil epidemiológico de pacientes em terapia renal substitutiva no Brasil. Rev. Saúde Pública, 2010; 44(4): 639-49

4 Lysaght MJ. Maintenance dialysis population dynamics: current trends and longterm implications. J Am Soc Nephrol 2002; 13: 37-40.

5 Ansell D, Feest T, eds. UK renal registry report 2004. Bristol: UK Renal Registry 2004.

6 United States Renal Data System (USRDS). 2004 annual report. Am J Kidney Dis 2005; 45 (suppl 1)

7 Hamer RA, Nahas AME. Editorial. The burden of chronic disease. BMJ 2006; $332: 563-4$

8 Instituto Brasileiro de Geografia e Estatística (IBGE). PNAD. Disponível em http://www.ibge.gov.br/home/estatistica/pesquisas/anos_anteriores.shtm.

9 Leite IC, Schramm JMA, Gadelha AMJ, Comparação das informações sobre as prevalências de doenças crônicas obtidas pelo suplemento saúde da PNAD/98 e as estimadas pelo estudo Carga de Doença no Brasil. Ciência \& Saúde Coletiva 2002; 7 (4): 733-741.

10 Moura L et al. Monitoring End Stage Renal Disease through the High Complexity Procedures Authorization Subsystem - Apac - in Brazil, 2000-2006. Epidemiol. Serv. Saúde, Brasília, 18(2):121-131, abr-jun 2009.

11 Kiberd BA, Clase CM. Cumulative risk for developing end-stage renal disease in the US population. J. Am. Soc. Nephrol 2002; 13:1635-44.

12 Berthoux F, Jones E, Geller R, Mendel S, Saker L, Briggs D, Epidemiological data of treated end-stage renal failure in the European Union (EU) during the year 1995: report of the European Renal Association Registry and the National Registries. Nephrol Dial Transplan 1999; 14: 2332-42. 
13 Locatelli F, Pozzoni P, Tentori F, Del Vecchio L. Epidemiology of cardiovascular risk in patients with chronic kidney disease. Nephrol Dial Transplant 2003; 7: 2-9.

14 Bastos RMR et al. Prevalência da doença renal crônica nos estágios 3/4 e 5 em adultos. Rev Assoc Med Bras 2009; 55(1):40-4.

15 Coresh J, Wei G, McQuillan G, Brancati F, Levey AS, Jones C, et al. Prevalence of high blood pressure and elevated serum creatinine level in the United States: findings from the National Health and Nutrition Examination Survey (1988-1994). Archives Intern Med 2001; 161: 1207-16.

16 Levin A, Identification of patients and risk factors in chronic kidney disease Evaluatting risk factors and therapeutic strategies. Nephrol Dial Transplant 2001; 16(7): $57-60$

17 Sarnak MJ, Levey AS, Schoolwerth AC, Coresh J, Culleton B, et al.: Kidney Disease as risk factor for development of cardiovasculae disease. A Statement from the American Association Councils on Kidney in Cardiovascular Disease, High Blood Pressure Research, Clinical, Cardiology, Epidemiology and Prevention. Circulation 2003; 108: 2154-74.

18 KDOQI clinical practice guidelines for Chronic Kidney Disease: evaluation, classification and stratification. American Journal Kidney Disease 2002; 39 (1): 221 - 26.

19 Guarnieri G, Faccini L, Lipartiti T, et al. Simple methods for nutritional assessment in hemodialyzed patients. Am J Clin Nutr 1980; 33:1598-607.

20 Acchiardo SR, Moore LW, Latour PA. Malnutrition as the main factor in morbidity and mortality of hemodialysis patients. Kidney Int Suppl 1983; 16: 199-203.

21 Marckmann P. Nutritional status and mortality of patients in regular dialysis therapy. J Intern Med 1989; 226:429-32.

22 Cuppari L, Kamimura MA. Avaliação nutricional na doença renal crônica: desafios na prática clínica. J Bras Nefrol 2009;31 (Supl 1):28-35.

23 Boxall MC, Goodship, THJ. Necessidades Nutricionais de Pacientes Submetidos à Hemodiálise. In Mitch WE, Klahr S. Manual of Nutrition and Kidney. Tecmedd Editora, São Paulo, 2008: 219-27.

24 Kalantar-Zadeh K, Kleiner M, Dunne E, Lee GH, Luft FC. A modified quantitative subjective global assessment of nutrition for dialysis patients. Nephrol Dial Transplant 1999; 14:1732-38. 
25 Segall L, Mardare NG, Ungureanu S, Busuioc M, Nistor I, Enache R et al. Nutritional status evaluation and survival in hemodialysis patients in one centre from Romania. Nephrol Dial Transplant 2009; 3: 1-5.

26 Kubrusly M, Oliveira CMC et al. Análise comparativa entre a albumina pré e pósdiálise como indicadores do risco nutricional e de morbimortalidade em hemodiálise. J Bras Nefrol 2012; 34(1):27-35.

27 Kidney Disease: Improving Global Outcomes (KDIGO) CKD Work Group. KDIGO 2012 Clinical Practice Guideline for the Evaluation and Management of Chronic Kidney Disease. Kidney Int (Suppl) 2013;3:1-150.

28 Augusto ALP, Alves DC, Manarino IC, Gerude M. Terapia Nutricional. Livraria Atheneu Editora, 1993: 173-87.

29 Guyton. Tratado de Fisiologia Médica. Guanabara Koogan, 1992: 300-09.

30 Ribeiro RCHM, Oliveira GASA, Ribeiro DF, Bertolin DC, Cesarino CB, Lima LCEQ, Oliveira SM. Caracterização e etilologia da insuficiência renal crônica em unidade de nefrologia do interior do Estado de São Paulo. Acta Paul Enferm 2008; 21 (Número Especial): 207-11.

31 SBN (Sociedade Brasileira de Nefrologia). Censos - 2015. [citado 13 dez 2011]. Disponível em: http://www.sbn.org.br

32 Riella, M.C, Martins C. Nutrição e o Rim. Guanabara Koogan. Rio de Janeiro. 2001: 416 .

33 United States Renal Data System (USRDS). 2014 annual report. Disponível em http://www.usrds.org/adr.aspx

34 Matos JPS, Lugon JR. Hora de conhecer a dimensão da doença renal crônica no Brasil. J Bras Nefrol 2014; 36 (3): 267-68.

35 Brasil. Ministério da Saúde. Portaria no 389, de 13 de março de 2014. Disponível em http://bvsms.saude.gov.br/bvs/saudelegis/gm/2014/prt0389_13_03_2014.html

36 Jones $\mathrm{CH}$, Akaba HC, Davi C, et al. The relationship between serum albumin and hydration status in hemodialysis patients. J Ren Nutr 2002;12: 209-12.

37 Wapensky T, Alexander SR, Sarwal M. Post-dialysis albumin: a better nutrition marker in pediatric hemodialysis patients? J Ren Nutr 2004;14: 45-51.

38 Manual MERCK. Disponível em http://www.manualmerck.net/images/p_628.gif

39 Sesso R, Lopes AA, Thome FS, Lugon JR, Burdmann Ede A. Brazilian dialysis census, 2009. J Bras Nefrol. 2010; 32: 374-8. 
40 SBN (Sociedade Brasileira de Nefrologia). Censos - 2013. Disponível em: http://www.sbn.org.br

41 KDOQI - National Kidney Foundation (homepage). Acessado em 5/2/2013, Disponível em http://www.kidney.org/professionals/kdoqi/

42 Nunes FT, Campos G, Paula SMX, Merhi VAL, Porteroo-Mclellan KC, Motta DG et al. Dialysis adequacy and nutritional status of hemodialysis patients. Hemodial Int. 2008; 12: $45-51$.

43 Fuchs V, Mostkoff D et al. Nutritional status in hospitalized patients in a public hospital in Mexico City. Nutr Hosp 2008; 23 (3): 294-303.

44 Martins C. Avaliação do Estado Nutricional e Diagnóstico. Vol I, Nutroclínica, 2008: 43.

45 Avesani CM. Avaliação de métodos para identificar desnutrição energético protéica de pctes em hemodiálise. J Bras Nefrol 2011; 33(1): 55-61.

46 Johansen KL, Young B, Kaysen GA, Chertow GM. Association of body size with outcomes among patients beginning dialysis. Am J Clin Nutr 2004; 80: 324-32.

47 Fouque D, Kalantar-Zadeh K, Kopple $\mathrm{J}$ et al. A proposed nomenclature and diagnostic criteria for protein- energy wasting in acute and chronic kidney disease. Kidney Int 2008; 73: 391-8.

48 Yeun JY, Kaysen GA. Factors influencing serum albumin in dialysis patients. Am J Kidney Dis. 198; 32(Suppl): S118-25.

49 Cabral PC, Diniz AS, Arruda IKG. Avaliação nutricional de pacientes em hemodiálise. Nutr Rev 2005; 18: 29-40.

50 Herselman M, Esau N, Kruger JM, et al. Relationship between serum protein and mortality in adults on long-term hemodialysis: exhaustive review and meta-analysis. Nutrition 2010; 26:10-32.

51 Combe C, Mccullough KP, Asano Y, et al. Kidney Disease Outcomes Quality Initiative (K/DOQI) and the Dialysis Outcomes and Practice Patterns Study (DOPPS): nutrition guidelines, indicators and practices. Am J Kidney Dis 2004; 44(Suppl): S39-S46.

52 Bower JD, Berman LB, Remmers R. et al. Whats is adequate dialysis? Proc, Clin. Dial. Transplant. Forum, 1971; 1:61-72.

53 Gotch FA, Sargent JA. A mechanistic analysis of the National Cooperative Dialysis Study. Kidney Int., 1985; 28:526-34. 
54 Young GA, Kopple JD, Lindholm B, Vonesh EF, De Vecchia A, Scalamogna A et al. Nutritional assessment of continuous ambulatory peritoneal dialysis patients: an international study. Am J Kidney Dis. 1991;17: 462-71.

55 Stefanelli C, Andreoti FA, Quesada KR, Detregiachi CRP. Avaliação nutricional de pacientes em hemodiálise. J Health Sci Inst. 2010; 28(3): 268-71

56 Cuppari L, Draibe SA, Anção MS, Sigulen D, Sustovich DR, Ajzen H et al. Avaliação nutricional de pacientes renais crônicos em programa de hemodiálise. Estudo multicêntrico. Rev Assoc Med Brasil. 1989; 35(1):9-14.

57 GeYQ, Wu ZL, XuYZ, Liao LT. Study on nutritional status of maintenance hemodialysis patients. Clin Nephrol. 1998; 50(5):309-14

58 Chertow GM, Johansen KL, Lew N, Lazarus JM, Lowrie EG. Vintage, nutritional status, and survival in hemodialysis patients. Kidney Int. 2000; 57(3):1176-81.

59 Sanches FM, Avesani CM, Kamimura MA, et al. Waist circumference and visceral fat in CKD: a cross-sectional study. Am J Kidney Dis 2008; 52: 66-73.

60 Oliveira CMVd. Reprodutibilidade do método da circunferência da cintura e sua validade como marcador de gordura visceral nos pacientes com doença renal crônica. Dissertação de Mestrado: Universidade Federal de São Paulo, 2008.

61 Ribeiro MMC, Araújo ML, Netto MP, Cunha LM. Impacto do hábito de jantar sobre o perfil dietético de pacientes em hemodiálise. J Bras Nefrol 2011; 33: 69-77.

62 Sesso R, Lopes AA, Thomé FS, Bevilacqua JL, Romão Jr JE, Lugon J. Relatório do Censo Brasileiro de Diálise. J Bras Nefrol; 2008, 30: 233-8.

63 Zambom MP, Belangero VMS, Britto ACG, Morcillo AM. Avaliação do Estado Nutricional de Crianças e Adolescentes com Insuficiência Renal Crônica. Rev Ass Med Brasil 2001; 47 (2): 137-40.

64 Kamimura MA et al. Métodos de avaliação da composição corporal em pacientes submetidos à hemodiálise. Rev Nutr 2004; 17/(1): 97-105.

65 Romão Jr JE, Doença Renal Crônica: Definição, Epidemiologia e Classificação. J Bras Nefrol, 2004; XXVI (3).

66 Bergström J. Why are dialysis patients malnourished? Am J Kidney Dis 1995; 26: 229-41.

67 Guarnieri G, Antonione R, Biolo G. Mechanisms of Malnutrition in uremia. J Renal Nutr 2003; 13:153-7.

68 Carvalhares JTA. Insuficiência Renal Crônica. In: Nóbrega, FJ. Clínica Pediátrica. Rio de Janeiro: Guanabara Koogan, 1987. 
69 Wills MR. Effects of renal failure. Clin. Biochem 1990, 23: 55-60.

70 Ryan TP, Sloand JA, Winters PC, Corsetti JP, Fisher SG. Chronic kidney disease prevalence and rate of diagnosis. Am J Med., 2007, 120: 981-6.

71 SBN (Sociedade Brasileira de Nefrologia). Censos - 2009. [citado 13 dez 2011]. Disponível em: http://www.sbn.org.br.

72 Oliveira GTC; Andrade EIG; Acurcio FA. et al. Avaliação nutricional de pacientes submetidos à hemodiálise em centros de Belo Horizonte. Assoc Med Bras 2012; 58(2): 240-47.

73 Barros E, Thomé F. Prevenção de doenças renais. In: Barros E, Manfro RC, Thomé F, Gonçalves LF, colaboradores. Nefrologia: rotinas, diagnóstico e tratamento. $2^{\mathrm{a}}$ ed. Porto Alegre: Artmed; 1999: 59-61.

74 Barreto ACP, Santello, JL, Manual de Hipertensão: entre a evidência e a prática clínica. São Paulo: Lemos Editorial; 2002: 137-9.

75 Porto, CC. Doenças do coração: prevenção e tratamento. Rio de Janeiro: Guanabara Koogan; 1998, 87: 453.

76 Chumlea, W. C.; Roche, A. F.; Steinbaugh, M. L. Estimating stature from knee height for persons 60 to 90 years of age. Journal American Geriatric Sociation; 1985, 33: 116-120.

77 Lohman TG, Roche AF et al. Anthropometric standardization reference manual. Champaign, Abridged Ed.: 1991.

78 Frisancho AR. New norms of upper limb fat and muscle areas for assessment of nutritional status. Am J Clin Nutr; 1981, 34: 2540-5.

79 Kopple JD et al. Relationship between nutritional status and the glomerular filtration rate: results from the MDRD study. Kidney Int 2000; 57 (4): 1688-703.

80 Lameire N. Management of the hemodialysis patient: an European perspective. In: Ronco C, Levin NW. Advances in end-stage renal disease. Basel: Karger; 2002: 93-100.

81 Kusumoto L et al. Adultos e idosos em hemodiálise: avaliação da qualidade de vida relacionada à saúde. Acta Paul Enferm, 2008; 21: 152-9.

82 Ribeiro RCHM et al. Caracterização e etiologia da insuficiência renal crônica em unidade de nefrologia do interior do Estado de São Paulo. Acta Paul Enferm 2008; 21: 20711.

83 Batista Filho M, Rissin A. A transição nutricional no Brasil: tendências regionais e temporais. Cad Saude Publica 2003; 19 (1): S181-191. 
84 Terra FS. Avaliação da Qualidade de Vida do Paciente Renal Crônico submetido à hemodiálise e sua adesão ao tratamento farmacológico de uso diário. Dissertação de mestrado, UNIFENAS, 2007

85 Nomura PI, Prudêncio LAR, Kohlmann Junior O. Características do indivíduo hipertenso. J Bras Nefr, 1995; 17/(1): 13-20.

86 Kaysen GA, Eiserich JP. The role of oxidative stress altered lipoprotein structure and function and microinflammation on cardiovascular risk in patients with minor renal disfunction. J Am Soc Nephrol, 2004; 15: 538-48

87 Valenzuela R, Giffoni A, Cuppari L, e Canziani M. Estado nutricional de pacientes com insuficiência renal crônica em hemodiálise no Amazonas. Rev Assoc Med Bras 2003; 49/(1): 72-8.

88 Blumenkrantz MJ, Kopple JD et al. Methods for assessing nutritional status of patients with renal failure. Am J Clin Nutr, 1980; 33: 1567-85.

89 Santos PR, Coelho MR, Gomes NP, Josue CEP. Associação de indicadores nutricionais com qualidade de vida em pacientes portadores de doença renal crônica em hemodiálise. J Bras Nefrol 2006, 23/(2): 57-64.

90 Bastos MG, Carmo WB, Abrita RR et al. Doença Renal Crônica: problemas e soluções. J Bras Nefrol 2004; XXVI (4): 202-15.

91 Marcen $\mathrm{R}$ et al. The impact of malnutrition in morbidity and mortality in stable HD patients. Nephrol Dial Transplant, 1997; 12: 2324-31.

92 Vegine PM, Fernandes ACP et al. Avaliação de Métodos para identificar desnutrição energético-protéica de pacientes em hemodiálise. J Bras Nefrol 2011; 33 (1): 55-61.

93 Barreto ACP, Santello, JL, Manual de Hipertensão: entre a evidência e a prática clínica. São Paulo: Lemos Editorial; 2002: 137-9.

94 Abreu PF, Ramos LR, Sesse R. Abnormalities of renal function in the elderly. Geriatr Nephrol Urol 1999; 9/(3): 151-54.

95 Araújo IC, Kamimura MA, Draibe SA, Canziani MEF, Manfredi SR, Avesani CM et al. Nutritional parameters and mortality in incident hemodialysis patients. J Renal Nutr. 2006; 16: 27-35.

96 Manente M. Avaliação da Reprodutibilidade dos Parâmetros de Adequação da Hemodiálise Crônica. Dissertação de mestrado, UFRGS, 2002.

97 Cuppari L, Kamimura MA. Nutritional evaluation in chronic kidney disease: challenges in clinical practice J Bras Nefrol 2009; 31/(Supl 1): 28-35. 
98 Grassman A, Gioberge S, Moeller S, Brown G. ESRD patients in 2004: global overview of numbers, treatment modalites and associated trends. Nephrol Dial Transplant, 2005; 20(12): 2587-93.

99 Calado I, França A, Santos A, e Filho N. Avaliação nutricional de pacientes renais em programa de hemodiálise em um hospital universitário de São Luis, Maranhão. J Bras Nefrol Volume 2007; 29/(4): 215-21. 


\section{ANEXOS}

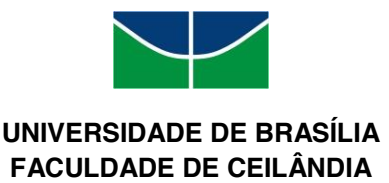

TERMO DE CONSENTIMENTO LIVRE E ESCLARECIDO - TCLE

O (a) Senhor (a) está sendo convidado (a) a participar do estudo chamado "Caracterização e Estado Nutricional de Portadores de Insuficiência Renal Crônica em Tratamento Hemodialítico no Distrito Federal'. O objetivo deste estudo é avaliar o estado nutricional de portadores de Insuficiência Renal Crônica em Hemodiálise no Distrito Federal.

O (a) Senhor (a) receberá todos os esclarecimentos necessários antes e no decorrer da pesquisa e Ihe asseguramos que seus dados pessoais serão mantidos em sigilo através da omissão total de quaisquer informações que permitam identificá-lo (a). Também asseguramos que o senhor (a) não terá despesas financeiras ou remuneração decorrentes da sua participação na pesquisa.

A sua participação incluirá responder um questionário após sua sessão de hemodiáliose com perguntas que incluem seu endereço, grau de escolaridade, nível sócio-econômico e informações sobre sua doença de base. O tempo estimado para o preenchimento do questionário é de 20 minutos. Não existe obrigatoriamente, um tempo pré-determinado, para responder o questionário. Informamos que o (a) Senhor (a) pode se recusar a responder qualquer questão que the traga constrangimento, podendo desistir de participar da pesquisa em qualquer momento sem nenhum prejuízo. Também solicitamos sua permissão e autorização para buscar no seu prontuário médico os resultados dos últimos exames de albumina e Kt/V. Em seguida faremos algumas medidas corporais (peso e altura). Com uma fita métrica serão feitas medidas no seu braço, punho e cintura. Com outro equipamento, chamado adipômetro, faremos algumas medidas para estimar a quantidade de gordura do seu corpo. As medidas serão feitas no braço, costas e cintura. A realização deste procedimento pode incomodar, pois é necessário puxar um pouco a pele no momento da medida, mas o incomodo é passageiro.

Os resultados da pesquisa serão divulgados em revista científica da área, não havendo qualquer identificação dos participantes. Os dados e materiais utilizados na pesquisa ficarão sobre a guarda do pesquisador. Em acordo com a Resolução 166/12, os pesquisadores asseguram ao participante ressarcimento de despesas decorrentes da pesquisa e indenização diante de eventuais danos decorrentes da pesquisa.

As pesquisadoras responsáveis pelo estudo estão a disposição para esclarecer qualquer dúvida: Prof $^{a}$ Kelb Bousquet Santos - Faculdade de Ceilândia (UnB) telefone: (61) 3376-0252; Nutricionista Luciane Costa (61) 9611-5093. Este projeto foi aprovado pelo Comitê de Ética em Pesquisa CEP/FS/UnB. O CEP está localizado na Faculdade de Ciências da Saúde da Universidade de Brasília, Campus Darcy Ribeiro, Asa Norte - Brasília, DF. Telefone de contato: 3107-1947

Este documento foi elaborado em duas vias, uma ficará com o pesquisador responsável e a outra com o sujeito da pesquisa. 
FICHA DE COLETA DE DADOS

Caracterização do Perfil e Estado Nutricional de Portadores de IRC em Hemodiálise no DF

Local da Coleta:

1-( )Público 2-( )Convênio Data Coleta:__/__/2014

Nome: DN

Raça/Cor 1( ) Parda 2( ) Negro $3\left(\begin{array}{ll}3( \\ \text { Branca }\end{array}\right.$ 4: ( ) Indígena 5 ( ) NI Idade:

Ocupação: Naturalidade: UF

Endereço:

PROCEDÊNCIA: $\quad$ 1-( ) DF 2-( ) GO 3-( ) MG 4-( ) Outro-Qual?

TIPO DE TRANSPORTE: 1-( ) Próprio 2-( ) Público 3-( ) Sanitário-SES/DF
GÊNERO:
1-( ) Masculino
2-( ) Feminino
ESCOLARIDADE:
1-( ) Analfabeto
2-( ) Lê e Escreve
3-( ) Ensino Fundamental Completo
4-( ) Ensino Fundamental Incompleto
5-( ) Ensino Médio Completo
6-( ) Ensino Médio Incompleto
7-( ) Ensino Superior Completo
11-( ) Ensino Superior Incompleto
8-( ) E 9-( ) M 10-( ) D
12-( ) Não Informado

RENDA:
1-( ) 1 a 2 SM
2-( ) 3 a 4 SM
3-( ) 5 a 6 SM
4-( ) 7 ou +SM
5-( ) Não Informado

Qual a sua percepção sobre o seu estado de saúde?

1( ) Muito Bom 2( ) Bom 3( ) Regular

4( ) Ruim

Doença de Base:

1-（ ) HAS (Hipertensão Arterial)

2-(...) DM (Diabetes Melitus)

(Etiologia)

3-( ) GNC (Glomerulonefrites Crônicas) 4-( ) Outros-Qual?

Peso Seco: Altura:

Perímetro do Pulso:

PCT: Cintura: Quadril: CB:

\section{TEMPO DE DIÁLISE:_________ meses}

ACESSO PARA DIÁLISE: 1 ( ) FAV 2 ( ) Catéter

EXAMES LABORATORIAIS: 3 últimos meses

\begin{tabular}{l|l|l|l} 
& MES 1 & MÊS 2 & MES 3 \\
\hline Albumina g/dl & & & \\
\hline $\mathrm{Kt} / \mathrm{V}$ & & &
\end{tabular}

Avaliadora: 


\section{NORMAS DA REVISTA}

ISSN 1415-5273 versão impressa e ISSN 1678-9865 versão on-line

\section{Escopo e política}

A Revista de Nutrição é um periódico especializado que publica artigos que contribuem para o estudo da Nutrição em suas diversas subáreas e interfaces. Com periodicidade bimestral, está aberta a contribuições da comunidade científica nacional e internacional.

Os manuscritos podem ser rejeitados sem comentários ós análise inicial, por pelo menos dois editores da Revista de os artigos forem considerados inadequados ou de prioridade ficiente para publicação na Revista.

\section{Categoria dos artigos}

A Revista aceita artigos inéditos em português, espanhol ou inglês, com título, resumo e termos de indexação no idioma original e em inglês, nas seguintes categorias:

Original: contribuições destinadas à divulgação de resultados de pesquisas inéditas, tendo em vista a relevância do tema, o alcance e o conhecimento gerado para a área da pesquisa (limite máximo de 5 mil palavras).

Especial: artigos a convite sobre temas atuais (limite máximo de 6 mil palavras).

Revisão (a convite): síntese de conhecimentos disponíveis sobre determinado tema, mediante análise e interpretação de bibliografia pertinente, de modo a conter uma análise crítica e comparativa dos trabalhos na área, que discuta os limites e alcances metodológicos, permitindo indicar perspectivas de continuidade de estudos naquela linha de pesquisa (limite máximo de 6 mil palavras). Serão publicados até dois trabalhos por fascículo.

Comunicação: relato de informações sobre temas relevantes, apoiado em pesquisas recentes, cujo mote seja subsidiar o trabalho de profissionais que atuam na área, servindo de apresentação ou atualização sobre o tema (limite máximo de 4 mil palavras). 
Nota Científica: dados inéditos parciais de uma pesquisa em andamento (limite máximo de 4 mil palavras).

Ensaio: trabalhos que possam trazer reflexão e discussão de assunto que gere questionamentos e hipóteses para futuras pesquisas (limite máximo de 5 mil palavras).

Seção Temática (a convite): seção destinada à publicação de 2 a 3 artigos coordenados entre si, de diferentes autores, e versando sobre tema de interesse atual (máximo de 10 mil palavras no total).

Categoria e a área temática do artigo: Os autores devem indicar a categoria do artigo e a área temática, a saber: alimentação e ciências sociais, avaliação nutricional, bioquímica nutricional, dietética, educação nutricional, epidemiologia e estatística, micronutrientes, nutrição clínica, nutrição experimental, nutrição e geriatria, nutrição materno-infantil, nutrição em produção de refeições, políticas de alimentação e nutrição e saúde coletiva.

\section{Pesquisas envolvendo seres vivos}

Resultados de pesquisas relacionadas a seres humanos e animais devem ser acompanhados de cópia de aprovação do parecer de um Comitê de Ética em pesquisa.

\section{Registros de Ensaios Clínicos}

Artigos com resultados de pesquisas clínicas devem apresentar um número de identificação em um dos Registros de Ensaios Clínicos validados pelos critérios da Organização Mundial da Saúde (OMS) e do Intemational Committee of Medical Journal Editors (ICMJE), cujos endereços estão disponíveis no site do ICMJE. O número de identificação deverá ser registrado ao final do resumo.

Os autores devem indicar três possíveis revisores para o manuscrito. Opcionalmente, podem indicar três revisores para os quais não gostaria que seu trabalho fosse enviado.

\section{Procedimentos editoriais}




\section{Autoria}

A indicação dos nomes dos autores logo abaixo do título do artigo é limitada a 6 . O crédito de autoria deverá ser baseado em contribuições substanciais, tais como concepção e desenho, ou análise e interpretação dos dados. Não se justifica a inclusão de nomes de autores cuja contribuição não se enquadre nos critérios acima.

Os manuscritos devem conter, na página de identificação, explicitamente, a contribuição de cada um dos autores.

Processo de julgamento dos manuscritos

Todos os outros manuscritos só iniciarão o processo de tramitação se estiverem de acordo com as Instruções aos Autores. Caso contrário, serão devolvidos para adequação às normas, inclusão de carta ou de outros documentos eventualmente necessários.

Recomenda-se fortemente que o(s) autor(es) busque(m) assessoria lingüística profissional (revisores e/ou tradutores certificados em língua portuguesa e inglesa) antes de submeter(em) originais que possam conter incorreções e/ou inadequações morfológicas, sintáticas, idiomáticas ou de estilo. Devem ainda evitar o uso da primeira pessoa "meu estudo...", ou da primeira pessoa do plural "percebemos....", pois em texto científico o discurso deve ser impessoal, sem juízo de valor e na terceira pessoa do singular.

Originais identificados com incorreções e/ou inadequações morfológicas ou sintáticas serão devolvidos antes mesmo de serem submetidos à avaliação quanto ao mérito do trabalho e à conveniência de sua publicação.

Pré-análise: a avaliação é feita pelos Editores Científicos com base na originalidade, pertinência, qualidade acadêmica e relevância do manuscrito para a nutrição.

Aprovados nesta fase, os manuscritos serão encaminhados aos revisores ad hoc selecionados pelos editores. Cada manuscrito será enviado para dois revisores de reconhecida competência na temática abordada, podendo um deles ser escolhido a partir da indicação dos autores. Em caso de desacordo, o original será enviado para uma terceira avaliação.

Todo processo de avaliação dos manuscritos terminará na segunda e última versão.

O processo de avaliação por pares é o sistema de blind review, 
procedimento sigiloso quanto à identidade tanto dos autores quanto dos revisores. Por isso os autores deverão empregar todos os meios possíveis para evitar a identificação de autoria do manuscrito.

Os pareceres dos revisores comportam três possibilidades: a) aprovação; b) recomendação de nova análise; c) recusa. Em quaisquer desses casos, o autor será comunicado.

Os pareceres são analisados pelos editores associados, que propõem ao Editor Científico a aprovação ou não do manuscrito.

Manuscritos recusados, mas com possibilidade de reformulação, poderão retornar como novo trabalho, iniciando outro processo de julgamento.

\section{Conflito de interesse}

No caso da identificação de conflito de interesse da parte dos revisores, o Comitê Editorial encaminhará o manuscrito a outro revisor ad hoc.

Manuscritos aceitos: manuscritos aceitos poderão retornar aos autores para aprovação de eventuais alterações, no processo de editoração e normalização, de acordo com o estilo da Revista.

Provas: serão enviadas provas tipográficas aos autores para a correção de erros de impressão. As provas devem retornar ao Núcleo de Editoração na data estipulada. Outras mudanças no manuscrito original não serão aceitas nesta fase.

\section{Preparo do manuscrito}

Submissão

de

trabalhos

Serão aceitos trabalhos acompanhados de carta assinada por todos os autores, com descrição do tipo de trabalho e da área temática, declaração de que o trabalho está sendo submetido apenas à Revista de Nutrição e de concordância com a cessão de direitos autorais e uma carta sobre a principal contribuição do estudo para a área.

Caso haja utilização de figuras ou tabelas publicadas em outras fontes, deve-se anexar documento que ateste a permissão para seu uso.

Enviar os manuscritos via site $<\underline{\mathrm{http}}$ :/www.scielo.br/rn $>$, preparados 
em espaço entrelinhas 1,5, com fonte Arial 11. O arquivo deverá ser gravado em editor de texto similar ou superior à versão 97-2003 do Word (Windows).

É fundamental que o escopo do artigo não contenha qualquer forma de identificação da autoria, o que inclui referência a trabalhos anteriores do(s) autor(es), da instituição de origem, por exemplo.

O texto deverá contemplar o número de palavras de acordo com a categoria do artigo. As folhas deverão ter numeração personalizada desde a folha de rosto (que deverá apresentar o número 1). O papel deverá ser de tamanho A4, com formatação de margens superior e inferior (no mínimo $2,5 \mathrm{~cm}$ ), esquerda e direita (no mínimo $3 \mathrm{~cm}$ ).

Os artigos devem ter, aproximadamente, 30 referências, exceto no caso de artigos de revisão, que podem apresentar em torno de 50. Sempre que uma referência possuir o número de Digital Object Identifier (DOI), este deve ser informado.

Versão reformulada: a versão reformulada deverá ser encaminhada via $<$ http://www.scielo.br/rn>. O(s) autor(es) deverá(ão) enviar apenas a última versão do trabalho.

O texto do artigo deverá empregar fonte colorida (cor azul) ou sublinhar, para todas as alterações, juntamente com uma carta ao editor, reiterando o interesse em publicar nesta Revista e informando quais alterações foram processadas no manuscrito, na versão reformulada. Se houver discordância quanto às recomendações dos revisores, o(s) autor(es) deverão apresentar os argumentos que justificam sua posição. O título e o código do manuscrito deverão ser especificados.

\section{Página de rosto deve conter}

a) título completo - deve ser conciso, evitando excesso de palavras, como "avaliação do....", "considerações acerca de..." 'estudo exploratório....";

b) short title com até 40 caracteres (incluindo espaços), em português (ou espanhol) e inglês;

c) nome de todos os autores por extenso, indicando a filiação institucional de cada um. Será aceita uma única titulação e filiação por autor. $\mathrm{O}(\mathrm{s})$ autor(es) deverá(ão), portanto, escolher, entre suas titulações e filiações institucionais, aquela que julgar(em) a mais importante.

d) Todos os dados da titulação e da filiação deverão ser apresentados por extenso, sem siglas.

e) Indicação dos endereços completos de todas as universidades às quais 
estão vinculados os autores;

f) Indicação de endereço para correspondência com o autor para a tramitação do original, incluindo fax, telefone e endereço eletrônico;

Observação: esta deverá ser a única parte do texto com a identificação dos autores.

Resumo: todos os artigos submetidos em português ou espanhol deverão ter resumo no idioma original e em inglês, com um mínimo de 150 palavras e máximo de 250 palavras.

Os artigos submetidos em inglês deverão vir acompanhados de resumo em português, além do abstract em inglês.

Para os artigos originais, os resumos devem ser estruturados destacando objetivos, métodos básicos adotados, informação sobre o local, população e amostragem da pesquisa, resultados e conclusões mais relevantes, considerando os objetivos do trabalho, e indicando formas de continuidade do estudo.

Para as demais categorias, o formato dos resumos deve ser o narrativo, mas com as mesmas informações.

O texto não deve conter citações e abreviaturas. Destacar no mínimo três e no máximo seis termos de indexação, utilizando os descritores em Ciência da Saúde - DeCS - da Bireme <http://decs.bvs.br>.

Texto: com exceção dos manuscritos apresentados como Revisão, Comunicação, Nota Científica e Ensaio, os trabalhos deverão seguir a estrutura formal para trabalhos científicos:

Introdução: deve conter revisão da literatura atualizada e pertinente ao tema, adequada à apresentação do problema, e que destaque sua relevância. Não deve ser extensa, a não ser em manuscritos submetidos como Artigo de Revisão.

Métodos: deve conter descrição clara e sucinta do método empregado, acompanhada da correspondente citação bibliográfica, incluindo: procedimentos adotados; universo e amostra; instrumentos de medida e, se aplicável, método de validação; tratamento estatístico.

Em relação à análise estatística, os autores devem demonstrar que os procedimentos utilizados foram não somente apropriados para testar as hipóteses do estudo, mas também corretamente interpretados. Os níveis de significância estatística (ex. $p<0,05 ; p<0,01 ; p<0,001)$ devem ser mencionados.

Informar que a pesquisa foi aprovada por Comitê de Ética credenciado 
junto ao Conselho Nacional de Saúde e fornecer o número do processo.

Ao relatar experimentos com animais, indicar se as diretrizes de conselhos de pesquisa institucionais ou nacionais - ou se qualquer lei nacional relativa aos cuidados e ao uso de animais de laboratório foram seguidas.

Resultados: sempre que possível, os resultados devem ser apresentados em tabelas ou figuras, elaboradas de forma a serem auto-explicativas e com análise estatística. Evitar repetir dados no texto.

Tabelas, quadros e figuras devem ser limitados a cinco no conjunto e numerados consecutiva e independentemente com algarismos arábicos, de acordo com a ordem de menção dos dados, e devem vir em folhas individuais e separadas, com indicação de sua localização no texto. É imprescindível a informação do local e ano do estudo. A cada um se deve atribuir um título breve. Os quadros e tabelas terão as bordas laterais abertas.

$\mathrm{O}(\mathrm{s})$ autor(es) se responsabiliza(m) pela qualidadedas figuras (desenhos, ilustrações, tabelas, quadros e gráficos), que deverão ser elaboradas em tamanhos de uma ou duas colunas ( 7 e $15 \mathrm{~cm}$, respectivamente); não é permitido o formato paisagem. Figuras digitalizadas deverão ter extensão jpeg e resolução mínima de 400 dpi.

Gráficos e desenhos deverão ser gerados em programas de desenho vetorial (Microsoft Excel, CorelDraw, Adobe Illustrator etc.), acompanhados de seus parâmetros quantitativos, em forma de tabela e com nome de todas as variáveis.

A publicação de imagens coloridas, após avaliação da viabilidade técnica de sua reprodução, será custeada pelo(s) autor(es). Em caso de manifestação de interesse por parte do(s) autor(es), a Revista de Nutrição providenciará um orçamento dos custos envolvidos, que poderão variar de acordo com o número de imagens, sua distribuição em páginas diferentes e a publicação concomitante de material em cores por parte de outro(s) autor(es).

Uma vez apresentado ao(s) autor(es) o orçamento dos custos correspondentes ao material de seu interesse, este(s) deverá(ão) efetuar depósito bancário. As informações para o depósito serão fornecidas oportunamente.

Discussão: deve explorar, adequada e objetivamente, os resultados, discutidos à luz de outras observações já registradas na literatura.

Conclusão: apresentar as conclusões relevantes, considerando os objetivos do trabalho, e indicar formas de continuidade do estudo. Não serão aceitas citações bibliográficas nesta seção. 
Agradecimentos: podem ser registrados agradecimentos, em parágrafo não superior a três linhas, dirigidos a instituições ou indivíduos que prestaram efetiva colaboração para o trabalho.

Anexos: deverão ser incluídos apenas quando imprescindíveis à compreensão do texto. Caberá aos editores julgar a necessidade de sua publicação.

Abreviaturas e siglas: deverão ser utilizadas de forma padronizada, restringindo-se apenas àquelas usadas convencionalmente ou sancionadas pelo uso, acompanhadas do significado, por extenso, quando da primeira citação no texto. Não devem ser usadas no título e no resumo.

\section{Referências de acordo com o estilo Vancouver}

Referências: devem ser numeradas consecutivamente, seguindo a ordem em que foram mencionadas pela primeira vez no texto, conforme o estilo Vancouver.

Nas referências com dois até o limite de seis autores, citam-se todos os autores; acima de seis autores, citam-se os seis primeiros autores, seguido de et al.

As abreviaturas dos títulos dos periódicos citados deverão estar de acordo com o Index Medicus.

Não serão aceitas citações/referências de monografias de conclusão de curso de graduação, de trabalhos de Congressos, Simpósios, Workshops, Encontros, entre outros, e de textos não publicados (aulas, entre outros).

Se um trabalho não publicado, de autoria de um dos autores do manuscrito, for citado (ou seja, um artigo in press), será necessário incluir a carta de aceitação da revista que publicará o referido artigo.

Se dados não publicados obtidos por outros pesquisadores forem citados pelo manuscrito, será necessário incluir uma carta de autorização, do uso dos mesmos por seus autores.

Citações bibliográficas no texto: deverão ser expostas em ordem numérica, em algarismos arábicos, meia linha acima e após a citação, e devem constar da lista de referências. Se forem dois autores, citam-se ambos ligados pelo "\&"; se forem mais de dois, cita-se o primeiro autor, seguido da expressão et al.

A exatidão e a adequação das referências a trabalhos que tenham sido consultados e mencionados no texto do artigo são de responsabilidade do autor. Todos os autores cujos trabalhos forem 
citados no texto deverão ser listados na seção de Referências.

\section{Exemplos}

\section{Artigo com mais de seis autores}

Oliveira JS, Lira PIC, Veras ICL, Maia SR, Lemos MCC, Andrade SLL, et al. Estado nutricional e insegurança alimentar de adolescentes e adultos em duas localidades de baixo índice de desenvolvimento humano. Rev Nutr. 2009; 22(4): 453-66. doi: 10.1590/S141552732009000400002.

\section{Artigo com um autor}

Burlandy L. A construção da política de segurança alimentar e nutricional no Brasil: estratégias e desafios para a promoção da intersetorialidade no âmbito federal de governo. Ciênc Saúde Coletiva. 2009; 14(3):851-60. doi: 10.1590/S1413-81232009000300020.

\section{Artigo em suporte eletrônico}

Sichieri R, Moura EC. Análise multinível das variações no índice de massa corporal entre adultos, Brasil, 2006. Rev Saúde Pública [Internet]. 2009 [acesso $2009 \mathrm{dez}$ 18]; 43(Suppl.2):90-7. Disponível em: $<$ http://www.scielo.br/scielo.php? $\quad$ script $=$ sci arttext\&pid $=S 0034-$ $89102009000900012 \& \operatorname{lng}=$ pt\&nrm=iso $>. \quad$ doi: $10.1590 /$ S003489102009000900012 .

\section{Livro}

Alberts B, Lewis J, Raff MC. Biologia molecular da célula. $5^{\text {a }}$ ed. Porto Alegre: Artmed; 2010.

\section{Livro em suporte eletrônico}

Brasil. Alimentação saudável para pessoa idosa: um manual para o profissional da saúde [Internet]. Brasília: Ministério da Saúde; 2009 [acesso 2010 jan 13]. Disponível em: $<$ http://200.18.252.57/services/ebooks/alimentacao_saudavel_idosa_profissionais_saude.pdf $>$.

\section{Capítulos de livros}

Aciolly E. Banco de leite. In: Aciolly E. Nutrição em obstetrícia e pediatria. $2^{\mathrm{a}}$ ed. Rio de Janeiro: Guanabara Koogan; 2009. Unidade 4.

\section{Capítulo de livro em suporte eletrônico}

Emergency contraceptive pills (ECPs). In: World Health Organization. Medical eligibility criteria for contraceptive use [Internet]. 4th ed. Geneva: WHO; 2009 [cited 2010 Jan 14]. Available from: 
$<\underline{\text { http://whqlibdoc.who.int/publications/2009/9789241563888 eng.pdf }>}$.

\section{Dissertações e teses}

Duran ACFL. Qualidade da dieta de adultos vivendo com HIV/AIDS e seus fatores associados [mestrado]. São Paulo: Universidade de São Paulo; 2009.

\section{Texto em formato eletrônico}

Sociedade Brasileira de Nutrição Parental e Enteral [Internet]. Assuntos de interesse do farmacêutico atuante na terapia nutricional. 2008/2009 [acesso 2010 jan 14]. Disponível em: $<$ http://www.sbnpe.com.br/ctdpg.php?.pg=13\&ct=A $>$.

\section{Programa de computador}

Software de avaliação nutricional. DietWin Professional [programa de computador]. Versão 2008. Porto Alegre: Brubins Comércio de Alimentos e Supergelados; 2008. Para outros exemplos recomendamos consultar as normas do Committee of Medical Journals Editors (Grupo Vancouver) $<$ http://www.icmje.org $>$.

Para outros exemplos recomendamos consultar as normas do Committee of Medical Journals Editors (Grupo Vancouver)

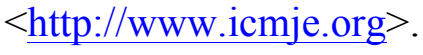

\section{Lista de checagem}

- Declaração de responsabilidade e transferência de direitos autorais assinada por cada autor. - Verificar se o texto, incluindo resumos, tabelas e referências, está reproduzido com letras fonte Arial, corpo 11 e entrelinhas 1,5 e com formatação de margens superior e inferior (no mínimo 2,5cm), esquerda e direita (no mínimo $3 \mathrm{~cm}$ ). - Indicação da categoria e área temática do artigo. - Verificar se estão completas as informações de legendas das figuras e tabelas. - Preparar página de rosto com as informações solicitadas. - Incluir o nome de agências financiadoras e o número do processo.

- Indicar se o artigo é baseado em tese/dissertação, colocando o título, o nome da instituição, o ano de defesa. - Incluir título do manuscrito, em português e em inglês. - Incluir título abreviado (short title), com 40 caracteres, para fins de legenda em todas as páginas. - Incluir resumos estruturados para trabalhos submetidos na categoria de originais e narrativos para manuscritos submetidos 
nas demais categorias, com um mínimo de 150 palavras e máximo de 250 palavras nos dois idiomas, português e inglês, ou em espanhol, nos casos em que se aplique, com termos de indexação

- Verificar se as referências estão normalizadas segundo estilo Vancouver, ordenadas na ordem em que foram mencionadas pela primeira vez no texto, e se todas estão citadas no texto. - Incluir permissão de editores para reprodução de figuras ou tabelas publicadas.

- Cópia do parecer do Comitê de Ética em pesquisa.

\section{Documentos}

\section{Declaração de responsabilidade e transferência de direitos autorais}

Cada autor deve ler e assinar os documentos (1) Declaração de Responsabilidade e (2) Transferência de Direitos Autorais, nos quais constarão:

- Título do manuscrito:

- Nome por extenso dos autores (na mesma ordem em que aparecem no manuscrito).

- Autor responsável pelas negociações:

1. Declaração de responsabilidade: todas as pessoas relacionadas como autoras devem assinar declarações de responsabilidade nos termos abaixo:

- "Certifico que participei da concepção do trabalho para tornar pública minha responsabilidade pelo seu conteúdo, que não omiti quaisquer ligações ou acordos de financiamento entre os autores e companhias que possam ter interesse na publicação deste artigo";

- "Certifico que o manuscrito é original e que o trabalho, em parte ou na íntegra, ou qualquer outro trabalho com conteúdo substancialmente similar, de minha autoria, não foi enviado a outra Revista e não o será, enquanto sua publicação estiver sendo considerada pela Revista de Nutrição, quer seja no formato impresso ou no eletrônico".

2. Transferência de Direitos Autorais: "Declaro que, em caso de aceitação do artigo, a Revista de Nutrição passa a ter os direitos autorais a ele referentes, que se tornarão propriedade exclusiva da Revista, vedado a qualquer reprodução, total ou parcial, em qualquer outra parte ou meio de divulgação, impressa ou eletrônica, sem que a prévia e necessária autorização seja solicitada e, se obtida, farei constar o competente agradecimento 
Assinatura do(s) autores(s) Data

Justificativa do artigo

Destaco que a principal contribuição do estudo para a área em que se insere é a seguinte:

(Escreva um parágrafo justificando porque a revista deve publicar o seu artigo, destacando a sua relevância científica, a sua contribuição para as discussões na área em que se insere, o(s) ponto(s) que caracteriza(m) a sua originalidade e o conseqüente potencial de ser citado) Dada a competência na área do estudo, indico o nome dos seguintes pesquisadores (três) que podem atuar como revisores do manuscrito. Declaro igualmente não haver qualquer conflito de interesses para esta indicação. 


\section{Comprovante de submissão do artigo para revista}

\section{Revista de Nutrição - Manuscript ID RN-2015-0014}

\section{Revista de Nutrição - Manuscript ID RN-2015-0014}

sbi.submissionrn@puc-campinas.edu.br (sbi.submissionrn@puc-campinas.edu.br)

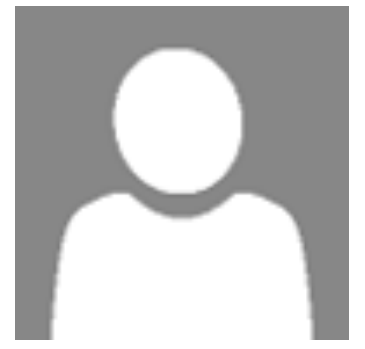

$11-F e b-2015$

Dear Mr. da Costa:

Your manuscript entitled "Nutritional status of patients with chronic renal failure on hemodialysis" has been successfully submitted online and is presently being given full consideration for publication in the Revista de Nutrição.

Your manuscript ID is RN-2015-0014.

Please mention the above manuscript ID in all future correspondence or when calling the office for questions. If there are any changes in your street address or e-mail address, please log in to ScholarOne Manuscripts at https://mc04.manuscriptcentral.com/rn-scielo and edit your user information as appropriate.

You can also view the status of your manuscript at any time by checking your Author Center after logging in tohttps://mc04.manuscriptcentral.com/rn-scielo.

Thank you for submitting your manuscript to the Revista de Nutrição. 
Submission

\title{
Confirmation
}

Thank you for submitting your manuscript to Revista de Nutricato.

\author{
Manuscript ID: RN-2015-0014 \\ Trie: Nutritional status of patients with chronic renal failure on hemodialysis \\ da Costa, Luciane \\ Authors: Bousquet Santos, Kelb \\ Date Submitted: 11-Feb-2015
}

Drint [D Return to Doshbosrd

Thomson Reuters | ScholarOne, Inc., 2014. All Rights Reserved.

ScholarOne Manuscripts and ScholarOne are registered trademarks of ScholarOne, Inc.

ScholarOne Manuscripts Patents \#7,257,767 and \#7,263,655.

y @ ScholarOneNews | $\%$ System Requirements | Q Privacy Statement | 
